\title{
Combating the Pandemic COVID-19: Clinical Trials, Therapies and Perspectives
}

\section{OPEN ACCESS}

Edited by:

Balakumar Chandrasekaran,

Philadelphia University, Jordan

Reviewed by:

Gaurav Kumar Jain,

Delhi Institute of Pharmaceutical

Sciences and Research, University

of Delhi, India

Bapi Gorain,

Taylor's University, Malaysia

*Correspondence:

Sabna Kotta

skotta@kau.edu.sa

Pran Kishore Deb

prankishore1@gmail.com;

pdeb@philadelphia.edu.jo

tORCID:

Sabna Kotta

orcid.org/0000-0001-6350-5733

Nabil Abdulhafiz Alhakamy

orcid.org/0000-0002-3826-1519

Shadab Md

orcid.org/0000-0002-9343-1066

Anroop B. Nair

orcid.org/0000-0003-2850-8669

Pran Kishore Deb

orcid.org/0000-0002-8650-2874

Specialty section:

This article was submitted to

Molecular Diagnostics

and Therapeutics,

a section of the journal

Frontiers in Molecular Biosciences

Received: 14 September 2020

Accepted: 19 October 2020

Published: 17 November 2020

Citation:

Kotta S, Aldawsari HM, Badr-Eldin SM, Alhakamy NA, Md S,

Nair AB and Deb PK (2020)

Combating the Pandemic COVID-19:

Clinical Trials, Therapies

and Perspectives.

Front. Mol. Biosci. 7:606393.

doi: 10.3389/fmolb.2020.606393

\author{
Sabna Kotta ${ }^{1 * t}$, Hibah Mubarak Aldawsari', Shaimaa M. Badr-Eldin ${ }^{1,2}$, \\ Nabil Abdulhafiz Alhakamy ${ }^{1+}$, Shadab Md ${ }^{1+}$, Anroop B. Nair ${ }^{3+}$ and Pran Kishore Deb ${ }^{4 * t}$ \\ 1 Department of Pharmaceutics, Faculty of Pharmacy, King Abdulaziz University, Jeddah, Saudi Arabia, ${ }^{2}$ Department of \\ Pharmaceutics and Industrial Pharmacy, Cairo University, Cairo, Egypt, ${ }^{3}$ Department of Pharmaceutical Sciences, College \\ of Clinical Pharmacy, King Faisal University, Al-Ahsa, Saudi Arabia, ${ }^{4}$ Department of Pharmaceutical Sciences, Faculty \\ of Pharmacy, Philadelphia University, Amman, Jordan
}

The coronavirus disease-19 (COVID-19) is caused due to the infection by a unique single stranded enveloped RNA virus, severe acute respiratory syndrome coronavirus2 (SARS-CoV-2). The COVID-19 has claimed many lives around the globe, and a promising solution to end this pandemic is still awaited. Till date neither an exact antiviral drug nor a vaccine is available in the market for public use to cure or control this pandemic. Repurposed drugs and supportive measures are the only available treatment options. This systematic review focuses on different treatment strategies based on various clinical studies. The review discusses all the current treatment plans and probable future strategies obtained as a result of a systematic search in PubMed and Science Direct database. All the possible options for the treatment as well as prophylaxis of COVID-19 are discussed. Apart from this, the article provides details on the clinical trials related to COVID-19, which are registered under ClinicalTrials.gov. Potential of drugs based on the previous researches on SARS-CoV, MERS-CoV, Ebola, influenza, etc. which fall under the same category of coronavirus are also emphasized. Information on cell-based and immunology-based approaches is also provided. In addition, miscellaneous therapeutic approaches and adjunctive therapies are discussed. The drug repurposing options, as evidenced from various in vitro and in silico models, are also covered including the possible future solutions to this pandemic.

Keywords: COVID-19, SARS-CoV-2, vaccine, convalescent plasma therapy, drug repurposing

\section{INTRODUCTION}

Coronavirus disease-19 (COVID-19) is a rapidly transmitted respiratory disease that has recently attracted the worldwide public health attention since its declaration as a pandemic by the World Health Organization (WHO) on March 11, 2020 (WHO, 2020). Severe acute respiratory syndrome coronavirus-2 (SARS-CoV-2), the novel coronavirus responsible for COVID-19, primarily attacks the human respiratory system. Several upsurges of coronaviruses have previously occurred, like the severe acute respiratory syndrome (SARS) and the Middle East respiratory syndrome (MERS); both syndromes were considered as significant public health warnings (De Wit et al., 2016). In December 2019, some patients in China were diagnosed with pneumonia of an undetermined underlying cause (Bogoch et al., 2020; Lu H. et al., 2020). Early reports anticipated the start of a new coronavirus 
upsurge that was named by the WHO as COVID-19, on February 11, 2020. The high rate of human-to-human transmission of COVID-19 infection resulted in the necessity of patients' isolation and a great urge for social distancing (Rothan and Byrareddy, 2020; Zhao et al., 2020).

Severe acute respiratory syndrome coronavirus-2 is the most recently discovered species of the coronaviruses $(\mathrm{CoV})$ that infects humans, and it is categorized as a new strain of beta $\mathrm{CoV}$. The genetics of the virus revealed above $80 \%$ similarity to SARS-CoV and above $50 \%$ to the MERS-CoV that originated in bats (Lu R. et al., 2020; Nadeem et al., 2020). Studies have been conducted to find a reservoir host or intermediate transmitter of the newly emerging virus. Early reports assume that two snake species as major reservoir of COVID-19. But, no evidences have been confirmed for animals other than bats and mammals as coronavirus reservoirs (Bassetti et al., 2020; Ji et al., 2020). Human-to-human transmission has been regarded as a likely mode of COVID-19 infection based on disease spreading within families and among people who were not exposed to animals (Graham Carlos et al., 2020; Helmy et al., 2020). Human-to-human transmission has been suggested to happen by unmediated contact or via droplets that outspread by coughing or sneezing from a person infected with the virus. Accordingly, the WHO has advised for keeping a distance of 1.5-2 $\mathrm{m}$ between people to reduce the likelihood of infection by nose or mouth droplets. However, the possibility of virus conveyance by airborne droplets over a distance of $2 \mathrm{~m}$ has been suggested by recent studies (Setti et al., 2020; van Doremalen et al., 2020).

The commonly identified clinical symptoms of COVID-19 disease are fever, dry cough, shortness of breath and excessive tiredness. Minor signs comprise of headache, sputum production, diarrhea, and lymphopenia (Borah et al., 2020; Ren et al., 2020). The symptoms, as mentioned earlier, are mostly revealed after an incubation period of about five days (Li Q. et al., 2020). A chest computed tomography (CT) scan in people with COVID19 presents the clinical features of pneumonia (Huang et al., 2020). However, there are additional abnormal manifestations, including acute respiratory distress, severe cardiac side effects, and the presence of ground glass like opacities were found in subpleural areas of lungs in many cases. These opacities are likely to cause systemic and localized immune reactions that result in an elevated inflammatory response. Sorrowfully, the treatment of some cases with interferon did not exhibit promising clinical effects. Instead, the pulmonary opacities showed progression with consequent worsening of the condition (Dong D. et al., 2020; Lei et al., 2020). Recently it was found that the disease exhibits a broad spectrum of clinical signs and symptoms. Various case studies reported the involvement of all the vital organs of the body including heart, lungs, GIT, liver, kidneys, and central nervous system (CNS). In severe cases multisystem involvement can be seen and might lead to worse clinical outcomes as well as increased mortality (Gavriatopoulou et al., 2020).

No exact antiviral drug or vaccine against COVID-19 has been discovered yet. The only available option, other than using symptom alleviating agents, is utilizing broad-spectrum antiviral drugs comprising protease inhibitors and nucleoside analogs in an attempt to attenuate the viral infection ( $\mathrm{Lu}, 2020)$.
Amongst the antivirals that are recently recorded as having some effects against COVID-19 are oseltamivir (anti-flu drug), lopinavir/ritonavir (anti-human immunodeficiency virus; antiHIV), and ganciclovir (Costanzo et al., 2020). High efficacy of the broad-spectrum antiviral remdesivir, which has been utilized for controlling the Ebola virus and the antimalarial agents like chloroquine and hydroxychloroquine, are also reported for controlling COVID-19 infection (Kumar et al., 2020; Ledford, 2020). Moreover, there are so many other molecules that are under development and testing. This article aims at reviewing the present and possible therapeutic options for the management of this emerging and widely spreading pandemic.

\section{METHOD}

We systematically searched the researches, reviews, and case reports in PubMed and Science Direct database, using the keywords COVID-19 and treatment, and selected the relevant articles. Some of the cross-references were also accessed. After selecting the potential agents for the COVID-19 treatment, again a search was conducted using the drug name AND COVID. The search is refined by the term "2020." The paper includes all the possible treatment strategies as well as all clinical trials for treatment or prevention of COVID-19 which are registered in NIH ClinicalTrials.gov.

\section{MECHANISM OF COVID-19 INFECTION AND POSSIBLE DRUG TARGETS}

The spike glycoprotein on the viral envelope is a major determinant of entry of virus to host cells by binding with its cellular receptor, angiotensin converting enzyme 2 (ACE-2). The viral infectivity and fusion are due to a significant proteolytic cleavage episode, and through clathrin-dependent as well as independent endocytosis. Once entered into the cells, the viruses release RNA which will synthesize two polyproteins and structural proteins, and starts replication. Then, the formation of nucleocapsid takes place by the combination of genomic RNA and nucleocapsid protein. Finally, the vesicles with viral particles combine with plasma membrane and discharge the viruses ( $\mathrm{Li}$ X. et al., 2020). Different therapeutic agents against COVID-19 target at one or more different stages of the replication cycle. The mechanism of replication COVID-19 inside host cell and possible drug targets are shown in Figure 1.

Various studies reported moderate to severe "cytokine storms" in severe patients. The "cytokine storm" which in turn leads to acute respiratory distress syndrome (ARDS), occurs due to the effects of combined action of several immunoactive molecules (Coperchini et al., 2020). This seems to be one of the most hazardous and life-threatening episodes in COVID-19. After binding to alveolar epithelial cells, the virus activates innate as well as the adaptive immune system. Following the SARS-CoV-2 infection macrophages are released as a response to inflammatory signals by type 2 cells. Cytokines are released by macrophages that in turn results in the release of more immune cells to the injury 


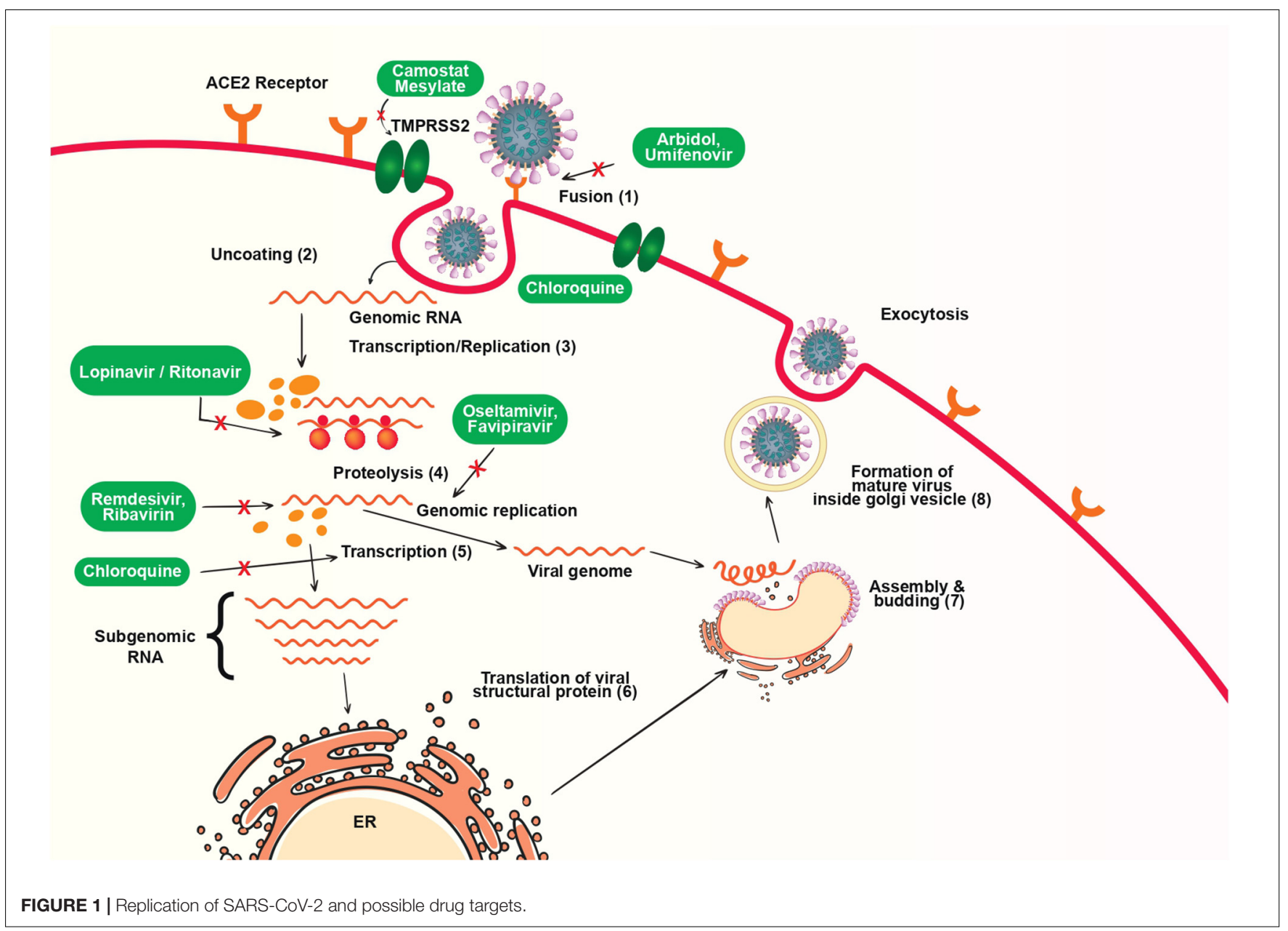

site. Cytokines cause vasodilatation also. Fluid accumulation in alveoli causes the damage of surfactant, and thus alveolar collapse which in turn affects the gas exchange. Further recruitment of neutrophils results in the release of reactive oxygen species (ROS) for destroying the infected cells. Also, the extensive release of cytokines occurs including interleukin-6 (IL-6), resulting in subsequent increase in the vascular permeability. This further leads to the entry of a large number of blood cells and fluid into the lungs, and causes dyspnea and respiratory failure (Zhang C. et al., 2020). The hyper-inflammation and cytokine storm syndrome is responsible ARDS and multi-organ failure. An illustration showing the effect of COVID-19 infection on the lungs is shown in Figure 2.

\section{CURRENT TREATMENT STRATEGIES}

Identifying effective therapeutic agents to fight this pandemic is urgently needed in this scenario ( $\mathrm{Li} \mathrm{H}$. et al., 2020). A simplified classification of therapeutic options against COVID19 is presented in Figure 3.

Drug repurposing is the only fastest approach to find potential candidates as a preventive or therapeutic measure for this new deadly pandemic (Ekins et al., 2020). Trials with ivermectin and hydroxychloroquine are examples of such an approach. At the same time, a large number of current researches are based on the testing of proven antiviral agents for related infections caused by SARS-CoV as well as MERS-CoV. The latter approach of the use of existing antiviral agents with proven efficiency against coronaviruses seems to be more promising. This argument could be justified by the fact that SARS-CoV-2 also belong to the same class of beta coronaviruses like SARS-CoV and MERS-CoV. Details of clinical trials on drug candidates against COVID-19 are presented in Table 1.

\section{Antiviral Agents Remdesivir}

Remdesivir is an investigational antiviral agent and also the first drug under clinical trial in the United States as an experimental cure for COVID-19 (Holshue et al., 2020). It possesses broad spectrum of action against different RNA viruses, such as MERS$\mathrm{CoV}$. Remdesivir and chloroquine are shown to be very efficient in the control of novel coronavirus infection in vitro (Li Q. et al., 2020). To understand the mechanism of inhibition, in a recent study, the MERS-CoV non-structural proteins were co-expressed in insect cells as a part of the polyprotein. The research demonstrated that remdesivir acts by inhibiting the 


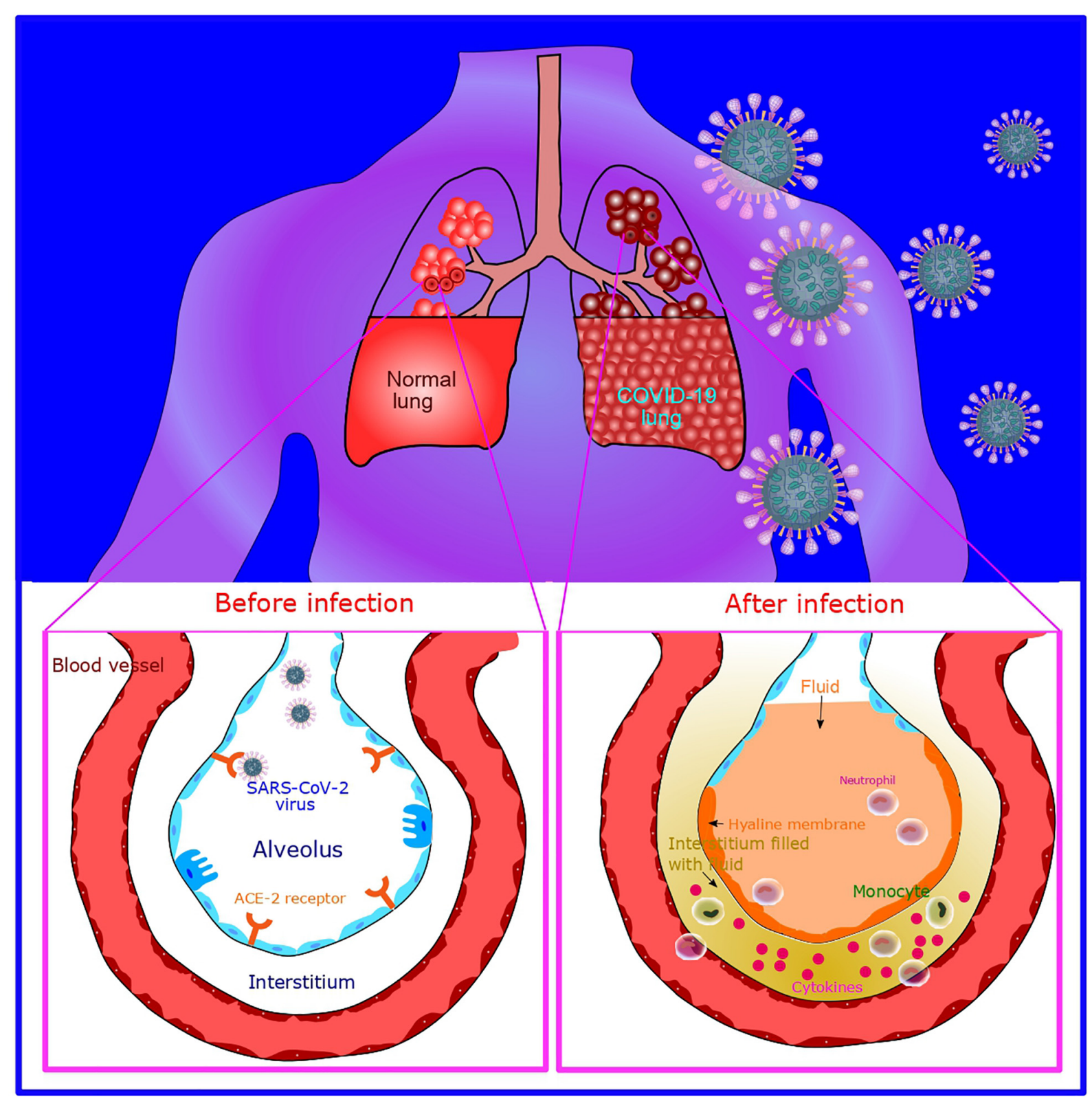

FIGURE 2 | Illustration of COVID-19 infection and its effect on the lungs. After SARS-CoV-2 infection, macrophages are released which subsequently causes cytokine release (cytokine storm). Further recruitment of neutrophills results in the release of reactive oxygen species (ROS) for destroying the infected cells. Further, fluid filling into the interstitial space and alveoli occurs.

nucleotide analog of RNA-dependent RNA polymerase (Gordon et al., 2020). An investigation in rhesus macaque model infection of MERS-CoV on preventive as well as the therapeutic potential of remdesivir revealed that the drug could reduce damage to the lungs and inhibit virus replication when administered either previous to or following infection (De Wit et al., 2020). The active metabolite of remdesivir can interact with both the active sites of enzyme and can produce delayed chain termination as well as distorted excision due to the ribose 1'-CN group, which is responsible for the enhanced antiviral action than other existing analogs (Shannon et al., 2020). Nine out of the ten ongoing clinical trials aim to evaluate the antiviral activity of remdesivir in SARS-Cov-2 infection. One of the studies is purely for the assessment of the adverse effects of the drug.

\section{Umifenovir (Arbidol ${ }^{\circledR}$ )}

Umifenovir is an antiviral agent that acts through multiple pathways and is effective against a variety of enveloped as well as non-enveloped DNA and RNA viruses. It is used for prophylaxis as well as treatment of influenza. It has been in use for more than 25 years in Russia and 14 years in China (Blaising et al., 2014). Since in vitro studies proved the efficacy 


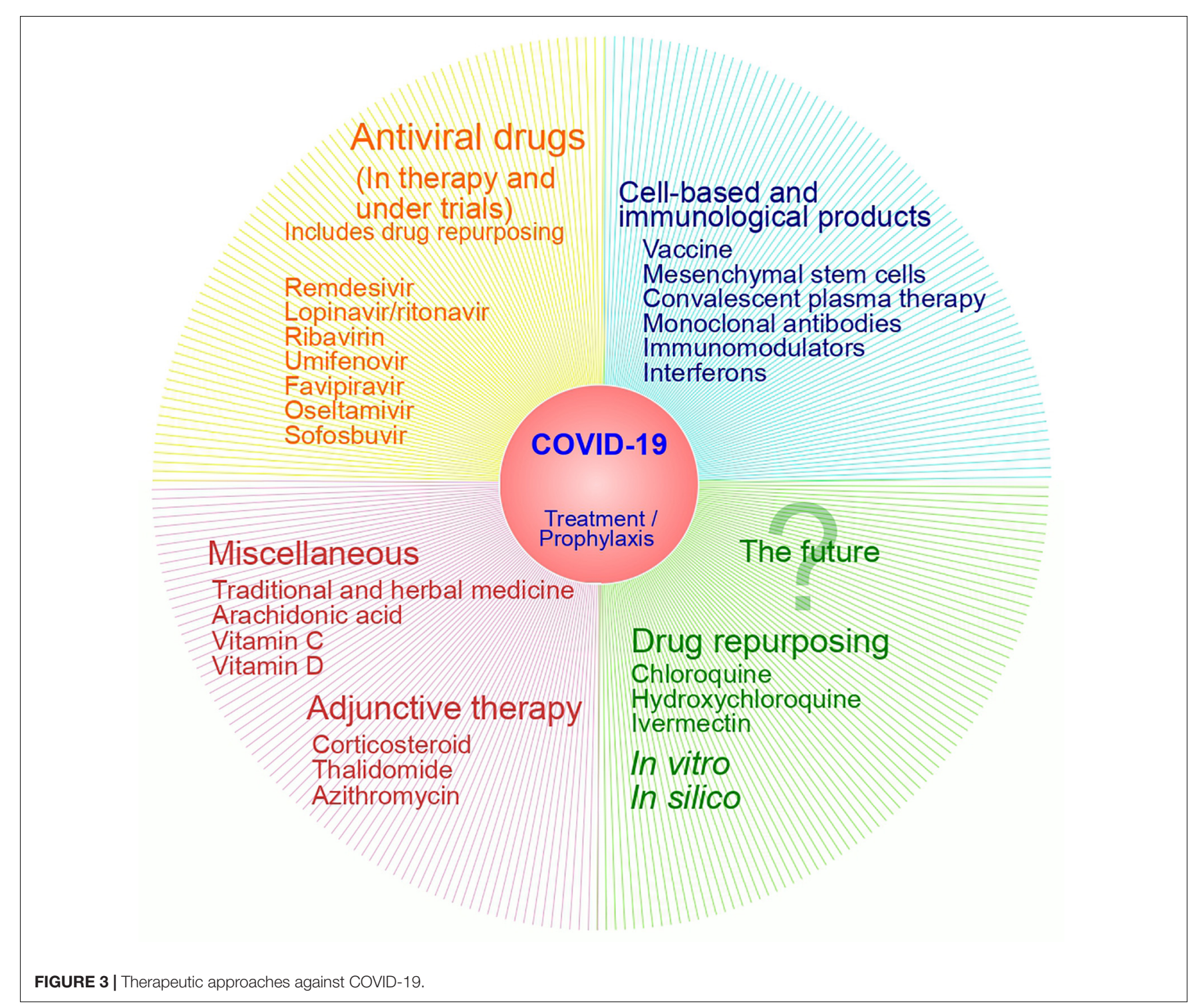

of this agent in SARS, it is being now used in the empirical therapy of COVID-19 in China (Song et al., 2020; Zhang J. et al., 2020). This drug is given orally for a maximum of 10 days at a dose of $200 \mathrm{mg}$, three times per day (Dong L. et al., 2020). In a study conducted in China, four patients administered with lopinavir/ritonavir, umifenovir, and one with traditional Chinese medicine along with essential support care. Three of them gained considerable relief from pneumonia, and two showed a negative viral test after the treatment period. The last patient with severe respiratory problems also showed significant improvement with this treatment procedure (Wang et al., 2020a). In a retrospective cohort study, $75 \%$ of the patients who took a combination of oral umifenovir and lopinavir/ritonavir recovered in 7 days as compared to $35 \%$ of patients who received lopinavir/ritonavir alone. And after 14 days, the viral clearance was achieved in $94 \%$ of the patients who received the drug combination, but it was only 69\% in the other group (Deng et al., 2020). Also, umifenovir treatment could increase the discharging rate as well as a decline in the mortality rate(Wang et al., 2020b). Four trials are registered in ClinicalTrials.gov on umifenovir for COVID-19.

\section{Lopinavir and Ritonavir}

Both of these drugs are antiretroviral protease inhibitors and co-administration of these drugs improves the pharmacokinetics of both. Ritonavir is a potent inhibitor of microsomal enzyme cytochrome P-450 3A4, so co-administration of ritonavir leads to the increased bioavailability and half-life of the co-administered lopinavir (Cooper et al., 2003). Lopinavir/ritonavir is given two times per day in a dose of $400 \mathrm{mg} / 100 \mathrm{mg}$ (Dong L. et al., 2020). After the lopinavir/ritonavir administration, coronavirus titers were null in a 54 years old male patient in Korea (Lim et al., 2020). In India, the Central Drugs Standard Control Organization agreed to use lopinavir/ritonavir therapy for 14 days with informed consent in high-risk categories who are symptomatic COVID-19 patients (Bhatnagar et al., 2020). Nevertheless, no benefit was observed in adult patients admitted 
TABLE 1 | Details of clinical trials on drug candidates against COVID-19.

\begin{tabular}{|c|c|c|c|c|c|}
\hline & Intervention/treatment & Study type/Phase & $\begin{array}{l}\text { Primary } \\
\text { purpose }\end{array}$ & $\begin{array}{l}\text { Number of } \\
\text { participants }\end{array}$ & Sponsor (ClinicalTrials.gov Identifier) \\
\hline 1 & Remdesivir & Interventional & Treatment & 453 & Capital Medical University (NCT04257656) \\
\hline 2 & Remdesivir & Interventional & Treatment & 308 & (Capital Medical University) NCT04252664 \\
\hline 3 & Remdesivir & Expanded Access & Treatment & & U.S. Army Medical Research and Development Command (NCT04302766) \\
\hline 4 & Remdesivir & Interventional & Treatment & 400 & Gilead Sciences (NCT04292899) \\
\hline 5 & Remdesivir & Interventional & Treatment & 600 & Gilead Sciences (NCT04292730) \\
\hline 6 & Remdesivir & Expanded Access & Treatment & - & Gilead Sciences (NCT04323761) \\
\hline 7 & Remdesivir & Interventional & Treatment & 440 & National Institute of Allergy and Infectious Diseases (NCT04280705) \\
\hline 8 & Hydroxychloroquine & Interventional Phase 3 & Treatment & 440 & Medical University of Vienna (NCT04336748) \\
\hline 9 & Hydroxychloroquine Remdesivir & Interventional & Treatment & 700 & Oslo University Hospital (NCT04321616) \\
\hline 10 & Chloroquine/hydroxychloroquine & Interventional Phase 2 & Prevention & 55000 & Washington University School of Medicine (NCT04333732) \\
\hline 11 & Chloroquine phosphate & Interventional & Treatment & 250 & Oxford University Clinical Research Unit, Vietnam (NCT04328493) \\
\hline 12 & Chloroquine & Interventional Phase 2, Phase 3 & Treatment & 210 & HaEmek Medical Center, Israel (NCT04333628) \\
\hline 13 & Chloroquine phosphate & Interventional Phase 3 & Treatment & 400 & $\begin{array}{l}\text { Wrocław Medical University } \\
\text { (NCT04331600) }\end{array}$ \\
\hline 14 & Chloroquine or Hydroxychloroquine & Interventional & Prevention & 4000 & University of Oxford (NCT04303507) \\
\hline 15 & Chloroquine analog, Nivolumab, Tocilizumab & Interventional Phase 2 & Treatment & 273 & Centre Leon Berard (NCT04333914) \\
\hline 16 & Chloroquine Diphosphate & Interventional Phase 2 & Treatment & 440 & Fundação de Medicina Tropical Dr. Heitor Vieira Dourado (NCT04323527) \\
\hline 17 & Azithromycin and Chloroquine & Interventional Phase 3 & Treatment & 1500 & Population Health Research Institute (NCT04324463) \\
\hline 18 & Azithromycin, Hydroxychloroquine & Interventional Phase 4 & Treatment & 226 & Chronic Obstructive Pulmonary Disease Trial Network, Denmark (NCT04322396) \\
\hline 19 & Darunavir and hydroxychloroquine & Interventional Phase 3 & Treatment & 3040 & Fundacio Lluita Contra la SIDA (NCT04304053) \\
\hline 20 & Hydroxychloroquine & Interventional Phase 3 & Treatment & 2486 & Gangnam Severance Hospital (NCT04330144) \\
\hline 21 & Hydroxychloroquine Sulfate & Interventional & Treatment & 220 & University Hospital, Akershus (NCT04316377) \\
\hline 22 & Hydroxychloroquine azithromycin & Interventional Phase 3 & Treatment & 440 & Hospital Israelita Albert Einstein (NCT04321278) \\
\hline
\end{tabular}


TABLE 1 | Continued

\begin{tabular}{|c|c|c|c|c|c|}
\hline & Intervention/treatment & Study type/Phase & $\begin{array}{l}\text { Primary } \\
\text { purpose }\end{array}$ & $\begin{array}{l}\text { Number of } \\
\text { participants }\end{array}$ & Sponsor (ClinicalTrials.gov Identifier) \\
\hline 23 & Hydroxychloroquine & Interventional & Treatment & 1300 & University Hospital, Angers (NCT04325893) \\
\hline 24 & $\begin{array}{l}\text { Levamisole, Budesonide, Formoterol, } \\
\text { Lopinavir/Ritonavir hydroxychloroquine }\end{array}$ & Interventional Phase 2 and 3 & Treatment & 30 & Fasa University of Medical Sciences (NCT04331470) \\
\hline 25 & $\begin{array}{l}\text { Carrimycin lopinavir/ritonavir Arbidol, } \\
\text { chloroquine phosphate }\end{array}$ & Interventional Phase 4 & Treatment & 520 & Beijing YouAn Hospital (NCT04286503) \\
\hline 26 & $\begin{array}{l}\text { Oseltamivir, Hydroxychloroquine } \\
\text { LopipinavirRitonavir, Darunavir Favipiravir }\end{array}$ & Interventional Phase 3 & Treatment & 80 & Rajavithi Hospital (NCT04303299) \\
\hline 27 & Favipiravir & Interventional & Treatment & 210 & Peking University First Hospital (NCT04333589) \\
\hline 28 & Favipiravir & Interventional Phase 3 & Treatment & 100 & Giuliano Rizzardini (NCT04336904) \\
\hline 29 & Arbidol & Interventional Phase 4 & Treatment & 380 & Jieming QU (NCT04260594) \\
\hline 30 & $\begin{array}{l}\text { ASC09(novel investigational protease inhibitor) } \\
\text { lopinavir/ritonavir }\end{array}$ & Interventional & Treatment & 160 & First Affiliated Hospital of Zhejiang University (NCT04261907) \\
\hline 31 & Lopinavir/ritonavir Hydroxychloroquine sulfate & Interventional phase 2 & Treatment & 150 & Asan Medical Center (NCT04307693) \\
\hline 32 & Lopinavir/ritonavir & Interventional phase 2 & Treatment & 440 & Sunnybrook Health Sciences Centre (NCT04330690) \\
\hline 33 & Hydroxychloroquine Lopinavir/ritonavir & Interventional Phase 3 & Treatment & 1200 & Centre Hospitalier Universitaire de Saint Etienne (NCT04328285) \\
\hline 34 & Hydroxychloroquine Oseltamivir Azithromycin & Interventional Phase 3 & Treatment & 500 & Shehnoor Azhar (NCT04338698) \\
\hline 35 & $\begin{array}{l}\text { lopinavir/ritonavir Hydroxychloroquine Sulfate } \\
\text { Losartan }\end{array}$ & Interventional Phase 2,3 & Treatment & 4000 & Bassett Healthcare (NCT04328012) \\
\hline 36 & Abidol hydrochloride, Oseltamivir Lopinavir/ritonavir & Interventional Phase 4 & Treatment & 400 & $\begin{array}{l}\text { Tongji Hospital } \\
\text { (NCT04255017) }\end{array}$ \\
\hline 37 & Lopinavir/ritonavir tablets Xiyanping injection & Interventional & Treatment & 80 & Jiangxi Qingfeng Pharmaceutical Co. Ltd. (NCT04295551) \\
\hline 38 & lopinavir/ritonavir and Traditional Chinese Medicines & Interventional & Treatment & 150 & Beijing 302 Hospital (NCT04251871) \\
\hline 39 & Methylprednisolone & Interventional Phase 2 & Treatment & 104 & University of Trieste (NCT04323592) \\
\hline 40 & Colchicine & Interventional Phase 3 & Treatment & 2500 & Estudios Clínicos Latino América (NCT04328480) \\
\hline 41 & Angiotensin 1-7 & Interventional Phase 2/3 & Treatment & 60 & Erasme University Hospital(NCT04332666) \\
\hline 42 & Thalidomide & Interventional Phase 2 & Treatment & 40 & First Affiliated Hospital of Wenzhou Medical University (NCT04273581) \\
\hline 43 & Thalidomide & Interventional Phase 2 & Treatment & 100 & First Affiliated Hospital of Wenzhou Medical University NCT04273529 \\
\hline 44 & Dietary Supplement: Natural Honey & Interventional Phase 3 & Treatment & 1000 & Misr University for Science and Technology (NCT04324489) \\
\hline
\end{tabular}


in the hospital due to severe COVID-19 with lopinavir/ritonavir therapy beyond standard care (Cao et al., 2020). More similar remarks were noticed and accordingly, the benefits of this combination are still doubtful (Kupferschmidt and Cohen, 2020). As a result, experts opined that the effectiveness of remdesivir and lopinavir/ritonavir should be confirmed by a randomized controlled trial. A retrospective data of pediatric patients with confirmed COVID-19 shows that all 36 children received interferon-alfa (INF $\alpha), 14$ received lopinavir/ritonavir, and 6 needed oxygen inhalation resulted in full recovery irrespective of the drug within $14 \pm 3$ days. Treatment with INF $\alpha$ along with lopinavir/ritonavir plus ribavirin showed a beneficial action in COVID-19 therapy (Yuan et al., 2020). At the same time, some reports expressed that the use of lopinavir/ritonavir along with adjuvant drugs should be encouraged for the treatment of patients with COVID-19 (Ye et al., 2020). More than 20 clinical trials are registered for the evaluation of this combination in COVID-19.

\section{Favipiravir}

Favipiravir, a derivative of pyrazine carboxamide, is a purine nucleic acid analog that interferes with the replication of the virus and inhibits RNA dependent RNA polymerase of RNA viruses. It possesses broad-spectrum antiviral activity and is effective against the influenza virus, bunyavirus, arenavirus, and filovirus (Du and Chen, 2020; Singh et al., 2020). An early result of a clinical trial reveals that favipiravir has more strong anti-viral activity than lopinavir/ritonavir with significantly less adverse effects (Chavez et al., in press; Zhai et al., 2020). Due to its efficacy on virus clearance, the Turkish ministry of health approved favipiravir for treating critical patients with Covid-19 pneumonia (Kodaz, 2020). Eleven clinical trials are registered for this drug in COVID19.

\section{Oseltamivir}

It is a neuraminidase inhibitor that hinders the neuraminidase enzyme expressed on the surface of the virus. This enzyme is needed for the release of the virus from the cells. It is approved for the prophylaxis as well as for the treatment of influenza ( $\mathrm{Li}$ et al., 2012). Five trials are registered for this drug in COVID-19 treatment and details are given in Table $\mathbf{1}$.

In the study by Ding et al. about the clinical characteristics of COVID-19 patients, all the 115 subjects received oseltamivir along with antibiotics and oxygen inhalation and all recovered without the need for intensive care unit (ICU; Ding et al., 2020). A 71-year-old woman tested positive for COVID-19 with a childhood history of psoriasis pointed out exacerbation of psoriasis after oseltamivir and hydroxychloroquine treatment. Hydroxychloroquine inhibits epidermal transglutaminase, which leads to the collection of the epidermal cells, and to date, there were no reports that oseltamivir may affect psoriasis. Thus, it could be reasonably argued that hydroxychloroquine may lead to a global increase in the number of psoriasis (Kutlu and Metin, 2020).

In the study conducted by Huang et al. (2020), all the 41 patients were given empirical antibiotic treatment, and 93\% received oseltamivir also, but the results are yet to be known.
A 43-year-old female patient was recovered and discharged from the hospital after the use of oseltamivir along with traditional Chinese medicine. Unfortunately, this patient showed a positive SARS-CoV-2 test again after 22 days of hospital discharge, however, convalescent plasma therapy (CPT) along with other measures made her condition better (Chen D. et al., 2020; Luo, 2020).

\section{Ribavirin}

Ribavirin is a guanosine analog and nucleoside inhibitor to stop viral RNA synthesis. It was widely used to treat SARS in combination with or without steroids in severe cases. Virtual screening of some FDA approved medicines against SARSCoV-2 main protease $\left(\mathrm{M}^{\text {pro }}\right)$ has been done and found that ribavirin, telbivudine, vitamin $\mathrm{B} 12$, and nicotinamide has an excellent docking score and can be made use in the treatment of COVID-19 (Kandeel and Al-Nazawi, 2020). In another molecular docking study, it was found that ribavirin, galidesivir, sofosbuvir, remdesivir, and tenofovir are effective agents in the treatment of COVID-19 since these drugs can tightly bind to the viral RNA dependent RNA polymerase (Elfiky, 2020). Since ribavirin shows the adverse effect of decreasing hemoglobin levels, it is not recommended for patients with respiratory distress (Jean et al., 2020). Out of the two clinical trials registered for this drug, one is completed, but results are not yet available.

\section{Cell-Based and Immunological Products Monoclonal Antibodies}

In COVID-19 infection, activation of a huge number of mononuclear macrophages and $\mathrm{T}$ lymphocytes occur which results in the production of cytokines such as IL-6. This IL-6 will bind to the IL- 6 receptor on the target cells, which leads to cytokine storm as well as dangerous inflammatory responses in the lungs and other organs (Xu et al., 2020).

Tocilizumab, a humanized monoclonal antibody that acts as a blocker of the IL- 6 receptor, can bind to the IL- 6 receptor with high affinity. It can prevent IL-6 itself from binding to its receptor, making it unable to injure the target cells, and lessen the inflammatory responses (Zhang C. et al., 2020). Its use is considered as one of the latest treatment strategies against COVID-19 (Bersanelli, 2020). The results of a retrospective study in fifteen COVID-19 patients, including moderate to critically ill, suggests that tocilizumab can be an efficient management option for patients with a risk of cytokine storms (Luo et al., 2020). Treatment with Tocilizumab, which blocks IL-6 receptors, results in notable outcomes like reduction in the elevated body temperature and improved respiratory function (Fu et al., 2020). Tocilizumab is also referred to as a promising choice for the treatment of the hyperinflammatory state associated with this infection in the second edition of "Vademecum for the Treatment of People With COVID-19" (Lombardy Section Italian Society Infectious And Tropical Diseases, 2020). In a COVID-19 patient with multiple myeloma, the treatment with tocilizumab was successful. The study recommends the need for randomized clinical trials for detailed evidence (Zhang X. et al., 2020). Further, several studies have been reported the use of tocilizumab as a promising treatment option for COVID-19 related respiratory 
failure (Bachanova et al., 2020; Bennardo et al., 2020; Buonaguro et al., 2020; Cellina et al., 2020; Ceribelli et al., 2020; Liu B. et al., 2020; Michot et al., 2020; Mihai et al., 2020).

Coronavirus neutralizing antibodies mainly aim the spike proteins on the surface of the virus, which mediate the entry into host cells. Receptor binding can generate irreversible conformational alteration in the spike proteins and thus inhibits the viral fusion with host cells (Wang C. et al., 2020). It is now suggested that CR3022, a SARS-CoV-specific human monoclonal antibody, has the potential to emerge as an agent against SARSCoV-2, along with other neutralizing antibodies (Tian et al., 2020). Sarilumab, gimsilumab, lenzilumab, etc. are the other monoclonal antibodies in the trial. More than 40 clinical trials on monoclonal antibodies are registered, including those on tocilizumab, sarilumab, gimsilumab, and lenzilumab. Details of selected clinical trials on biological agents against COVID-19 are provided in Table 2.

\section{Interferons}

Interferons are signaling proteins and have antiviral activity. Viruses trigger the release of interferons by the host cells. Type 1 interferons possess a wide range of antiviral effects in vitro and a recent clinical trial proved its efficacy in the treatment of MERS$\mathrm{CoV}$. With regard to this, interferon wastried in clinical trials as a treatment option for COVID-19. The $\beta$ subtype is found more promising, and the treatment in the early stages of the infection is recommended (Sallard et al., 2020). The combination of ribavirin and INF $\alpha$ has been the most commonly used therapy to treat MERS outbreaks in South Korea (Kim et al., 2016). Due to the effectiveness of this therapy, this combination is recommended to treat COVID-19 infection in the fifth edition of the National Health Commission's Regimen of China (Du et al., 2020).

\section{Mesenchymal Stem Cells}

The human umbilical cord mesenchymal stem cell (MSC) possesses outstanding immunomodulatory and strong antiinflammatory functions with proper safety (Metcalfe, 2020). Liang et al. (2020) reported that treatment with allogeneic human umbilical cord MSCs in a 65-year-old critically ill female patient with COVID-19 showed a significant and positive outcome with good tolerance. So this kind of therapy is an ideal choice for the management of seriously ill COVID-19 patients (Liang et al., 2020). In another study, seven patients who are dangerously ill with COVID-19, MSCs therapy significantly improved their condition without any adverse effects (Leng et al., 2020). Therefore, MSC therapy is a safe and effective option for critical cases of pneumonia associated with COVID-19. Even though the results are promising, proper clinical investigations are required for these kinds of cell-based therapies (Khoury et al., 2020). A total of 29 clinical trials are registered for the efficacy and safety evaluation of MSCs in COVID-19.

\section{Convalescent Plasma Therapy}

Convalescent plasma therapy is considered one of the advanced options sought for the treatment of COVID-19 (Zhao and $\mathrm{He}, 2020)$. Convalescent or immune plasma is the plasma collected from individuals who are cleared of infection with a sufficient amount of developed and antibodies. Convalescent plasma therapy will help to get immediate immunity for a short time in susceptible individuals (Bloch et al., 2020). Neutralizing antibodies are critical in virus clearance and vital in defense against various viral diseases. Passive immunity achieved due to convalescent plasma can provide neutralizing antibodies that can control the infection. In addition to antiviral action, convalescent plasma can also cause immunomodulation. Some antibodies can cause the inhibition of complement cascade and thus can control the formation of immune complexes. Convalescent plasma has anti-inflammatory effects also due to the action of a network of autoantibodies and can manage an overactive immune system. The effectiveness of this therapy is highly related to the concentration of neutralizing antibodies in the collected plasma (Rojas et al., 2020). A brief mechanism of CPT is depicted in Figure 4.

Despite this apparent advantage, several challenges are also associated with CPT such as anaphylactic reactions, transfusion transmitted infections, transfusion associated acute lung injury, circulatory overload, hemolysis, etc. Owing to the importance of this approach, the possibilities and challenges of CPT are now well discussed and described (Roback and Guarner, 2020).

From the previous studies related to SARS, it was reported that CPTresulted in a shorter hospital stay period as well as a lower death rate as compared to the control group (Soo et al., 2004; Cheng et al., 2005; Chen L. et al., 2020). Five seriously sick patients with COVID-19 showed promising results when received plasma transfusion. After the transfusion, body temperature and viral loads were declined and turned to negative within 12 days (Shen et al., 2020). In another study, a single dose of $200 \mathrm{~mL}$ of convalescent plasma antibody titers over 1:640 was transfused to 10 patients along with antiviral agents and supportive measures. The results confirmed that this therapy was well tolerated and could be able to neutralize viremia in critical COVID-19 cases (Duan et al., 2020).

In April 2020, the US FDA permitted CPT in dangerously sick patients with COVID-19 (Tanne, 2020). Two COVID-19 patients with severe pneumonia and ARDS showed a positive result by CPT along with corticosteroids (Ahn et al., 2020). A good number of clinical trials are registered for studying the safety and efficacy evaluation of CPT in COVID-19 patients (Table 3). Many clinical results showed that CPT produces remarkable improvement in clinical symptoms as well as radiological and biochemical parameters related with the SARS-CoV-2 infection (Bakhtawar et al., 2020).

\section{Vaccines}

Vaccine development needs many years to reach the market under normal circumstances. Fortunately, the data generated in the research on SARS-CoV as well as MERS-CoV helped in an express design and development of the COVID-19 vaccine. Thus, within three months of the emergence of COVID-19, a specific vaccine candidate entered Phase I clinical trials, and WHO announced the news of the availability of licensed vaccine for widespread use by the middle of 2021. Presently, different SARS$\mathrm{CoV}$ and MERS-CoV vaccine candidate are in clinical trials against COVID-19. At the same time, thorough investigations 
TABLE 2 | Details of clinical trials on biological agents against COVID-19.

\begin{tabular}{|c|c|c|c|c|c|}
\hline No. & Intervention/treatment & Study type/Phase & Primary purpose & $\begin{array}{l}\text { No. of } \\
\text { participants }\end{array}$ & $\begin{array}{l}\text { Sponsors and Collaborators (ClinicalTrials.gov } \\
\text { Identifier) }\end{array}$ \\
\hline 1 & $\begin{array}{l}\text { Lopinavir/ritonavir Hydroxychloroquine sulfate Baricitinib } \\
\text { (Janus kinase inhibitor) Sarilumab (anti-IL-6 receptor) }\end{array}$ & Interventional (Phase 2) & Treatment & 1000 & $\begin{array}{l}\text { Lisa Barrett, Nova Scotia Health Authority } \\
\text { (NCT04321993) }\end{array}$ \\
\hline 2 & $\begin{array}{l}\text { Xiyanping injection Lopinavir/ritonavir, alpha-interferon } \\
\text { nebulization }\end{array}$ & Interventional (Phase 2,3) & Treatment & 348 & $\begin{array}{l}\text { Jiangxi Qingfeng Pharmaceutical Co. Ltd. } \\
\text { (NCT04275388) }\end{array}$ \\
\hline 3 & $\begin{array}{l}\text { Remdesivir Lopinavir/ritonavir, Interferon Beta-1A, } \\
\text { Hydroxychloroquine }\end{array}$ & Interventional & Treatment & 3100 & $\begin{array}{l}\text { Institut National de la Santé Et de la Recherche } \\
\text { Médicale, France (NCT04315948) }\end{array}$ \\
\hline 4 & $\begin{array}{l}\text { lopinavir/ritonavir, remdesivir, interferon beta-1a, } \\
\text { chloroquine and/or azithromycin }\end{array}$ & Observational & Adverse events & 1000 & Groupe Hospitalier Pitie-Salpetriere (NCT04314817) \\
\hline 5 & $\begin{array}{l}\text { Hydrocortisone, Ceftriaxone, Moxifloxacin, Levofloxacin, } \\
\text { Piperacillin-tazobactam, Ceftaroline, Amoxicillin, } \\
\text { clavulanate, Macrolide, oseltamivir, Lopinavir/ritonavir } \\
\text { Hydroxychloroquine Interferon- } \beta 1 \text { a Anakinra }\end{array}$ & Interventional & Treatment (Phase 4) & 6800 & MJM Bonten (NCT02735707) \\
\hline 6 & Lopinavir/ritonavir, Ribavirin, Interferon Beta-1B & Interventional (Phase 2) & Treatment & 70 & The University of Hong Kong (NCT04276688) \\
\hline 7 & $\begin{array}{l}\text { ASCO9F } \\
\text { Oseltamivir } \\
\text { Ritonavir } \\
\text { Oseltamivir }\end{array}$ & Interventional (Phase 3) & Treatment & 60 & Tongji Hospital (NCT04261270) \\
\hline 8 & $\begin{array}{l}\text { Hydroxychloroquine } \\
\text { Lopinavir/Ritonavir } \\
\text { Interferon Beta-1A } \\
\text { Interferon Beta-1B }\end{array}$ & Interventional (Phase 4) & Treatment & 60 & Shahid Beheshti University of Medical Sciences \\
\hline 9 & Abidol Hydrochloride Interferon & Interventional (Phase 4) & Treatment & 100 & Tongji Hospital (NCT04254874) \\
\hline 10 & $\begin{array}{l}\text { Recombinant human interferon Alpha- } 1 \mathrm{~b} \\
\text { thymosin alpha } 1\end{array}$ & Interventional (Phase 3) & prevention & 2944 & $\begin{array}{l}\text { Shanghai Jiao Tong University School of Medicine } \\
\text { (NCT04320238) }\end{array}$ \\
\hline 11 & Ganovo, ritonavir, Interferon & Interventional (Phase 4) & Treatment & 11 & The Ninth Hospital of Nanchang (NCT04291729) \\
\hline 12 & Recombinant human interferon $\alpha 1 \beta$ & Interventional (early Phase 1) & Treatment & 328 & Tongji Hospital (NCT04293887) \\
\hline 13 & $\begin{array}{l}\text { Bromhexine Hydrochloride, Arbidol Hydrochloride } \\
\text { Recombinant Human Interferon } \alpha 2 \mathrm{~b}\end{array}$ & Interventional & Treatment & 60 & $\begin{array}{l}\text { Second Affiliated Hospital of Wenzhou Medical } \\
\text { University (NCT04273763) }\end{array}$ \\
\hline 14 & $\begin{array}{l}\text { Emapalumab(Anti-interferon Gamma) } \\
\text { Anakinra (Interleukin-1Receptor Antagonist) }\end{array}$ & Interventional (Phase 2/3) & Treatment & 54 & Swedish Orphan Biovitrum (NCT04324021) \\
\hline 15 & Tocilizumab & Observational & Treatment & 30 & University of L'Aquila (NCT04332913) \\
\hline 16 & $\begin{array}{l}\text { Favipiravir } \\
\text { Tocilizumab }\end{array}$ & Interventional & Treatment & 150 & Peking University First Hospital (NCT04310228) \\
\hline 17 & INO-4800, a Prophylactic Vaccine & Interventional (non-randomized) & Prevention & 40 & Inovio Pharmaceuticals (NCT04336410) \\
\hline 18 & Biological: UC-MSCs & Interventional & Prevention & 10 & ZhiYong Peng (NCT0426952) \\
\hline 19 & Biological: ChAdOx1 nCoV-19 & Interventional (Phase 1/2) & Treatment & 510 & University of Oxford (NCT04324606) \\
\hline 20 & $\begin{array}{l}\text { Tocilizumab } \\
\text { Sarilumab }\end{array}$ & Interventional (Phase 2) & Treatment & 200 & Marius Henriksen (NCT04322773) \\
\hline 21 & $\begin{array}{l}\text { Siltuximab } \\
\text { Methylprednisolone }\end{array}$ & Interventional (Phase 2) & Treatment & 100 & Judit Pich Martínez (NCT04329650) \\
\hline 22 & Tocilizumab Pembrolizumab (MK-3475) & Interventional (Phase 2) & Treatment & 24 & MedSIR (NCT04335305) \\
\hline
\end{tabular}




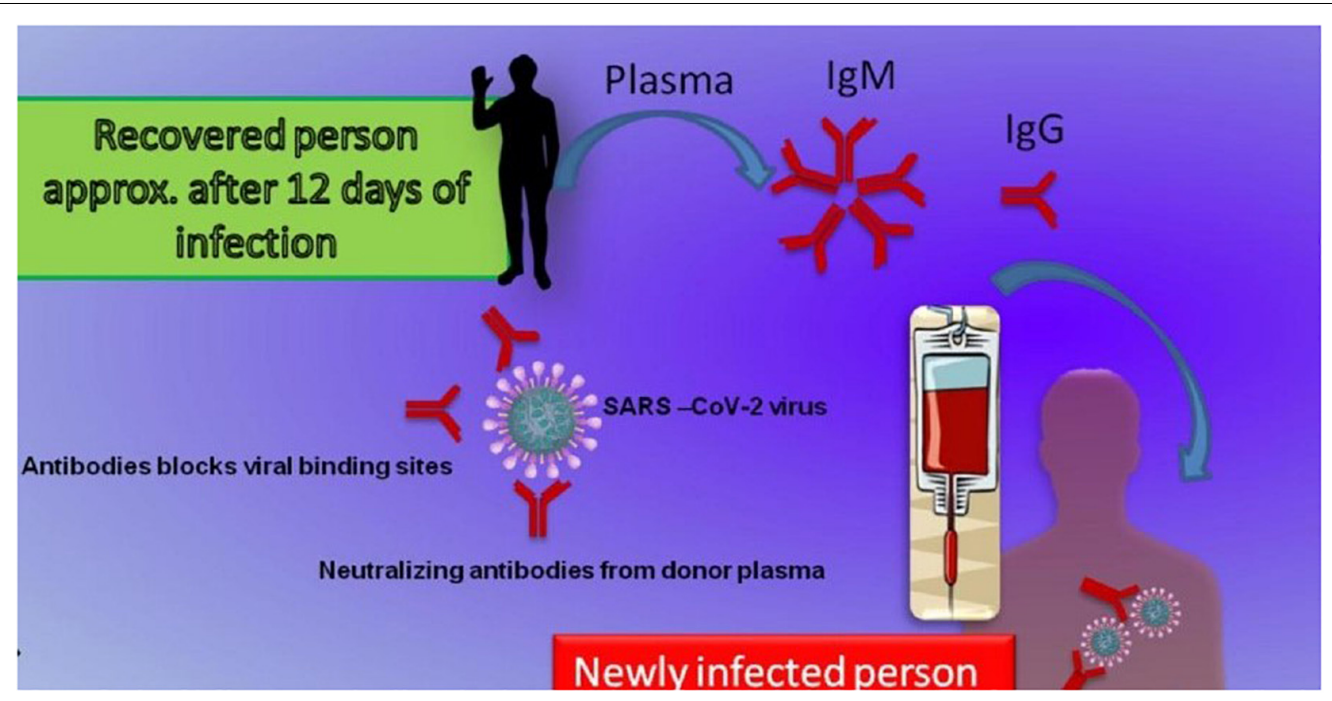

FIGURE 4 | Schematic representation of the convalescent plasma therapy along with its mechanisms of action. A person recovered from COVID-19 infection produces a sufficient amount of specific antibodies in 12-14 days. The plasma with neutralizing antibodies mainly IgM and IgG can be transferred to produce immediate immunity in suspected or infected persons. IgG and IgM anti-SARS-CoV-2 antibodies will bind to specific sites and neutralize the virus.

are required urgently to study the risk of immune enhancement. Therefore, along with early clinical trials, clinical evidence is also needed to support the possibility of immune enhancement (de Alwis et al., 2020). According to the latest WHO report there are more than 169 COVID-19 vaccine candidates currently under clinical trials. Among these clinical candidates, 26 are in the various phase of human trials and 10 reached up to phase 3 of the clinical trial. Figure 5 shows some of the ongoing vaccine trials in lead which are specific to COVID-19.

\section{Miscellaneous/Adjunctive Therapy} Traditional Chinese Medicine

Various Traditional Chinese Medicines like Shuanghuanglian oral liquid and Lianhuaqingwen capsule were also tried for treating SARS-CoV-2 infection and found satisfactory outcome. Some of them, like YinHu QingWen, Fuzheng Huayu, are in registered clinical trials (Wang L. et al., 2020). A total of 8 clinical trials are registered for the evaluation of the effectiveness of Traditional Chinese Medicine.

\section{Vitamins}

An adequate level of vitamin $\mathrm{D}$ is required to suppress the adhesion molecule (CD26), which helps in invasion to host cells. Since, vitamin D deficiency leads to increased risk of respiratory infections, supplementation with adequate dose is highly recommended in high-risk categories (McCartney and Byrne, 2020). Clinical studies show that a large dose of vitamin $\mathrm{C}$ can prevent viral infections. Thus, early use of antioxidants like vitamin $\mathrm{C}$ in large doses may be helpful to fight COVID-19 (Cheng, 2020).

\section{Corticosteroids}

Even though corticosteroids are used as adjuvant therapy in COVID-19 infection, WHO and the United States Centre for
Disease Control and Prevention recommend that it should not be regularly used in COVID-19 patients, except indicated for other conditions. Low to moderate doses with close monitoring as a short course may be beneficial. More than ten trials are registered for the evaluation or comparison of the safety as well as efficacy of different corticosteroids in COVID-19 (Rosa and Santos, 2020).

\section{Thalidomide}

The severe lung injury in COVID 19 may be related to the extreme immune response as a result of cytokine storm. Thalidomide is an immunomodulatory agent, and it can stimulate $\mathrm{T}$ cells, decrease TNF- $\alpha$ production, and enhance the secretion of interleukins and natural killer cells. Its antiinflammatory role is due to the capacity to reduce TNF- $\alpha$ by enhancing the degradation of mRNA in blood cells. Two trials are registered to test the safety and effectiveness of thalidomide in treating moderate or severe COVID-19 (Newfield, 2018).

\section{Drug Repurposing Approach Chloroquine or Hydroxychloroquine}

Chloroquine is a popular drug used for the prophylaxis of malaria and amebiasis and also to treat autoimmune diseases like rheumatoid arthritis and lupus erythematosus. A wide range of mechanisms has been proposed for the action of chloroquine (Cortegiani et al., 2020). By altering the binding of the virus to the cell surface receptor, it can hold back the pre-entry step to the host cell (Vincent et al., 2005). Also, it can impair pH reliant endosome dependent entrance of enveloped viruses like chikungunya and dengue viruses (Gay et al., 2012; Wong and $\mathrm{Chu}, 2018$ ). Post-translational variation of viral proteins can also be damaged by chloroquine. It can also spoil the viral protein maturation (Devaux et al., 2020). In addition, it acts as an immunomodulatory agent by the regulation of pro-inflammatory cytokines and cell signaling. 


\begin{tabular}{|c|c|c|c|c|c|}
\hline No. & Intervention/treatment & Study type/Phase & Primary purpose & Number of participants & Sponsors and Collaborators (ClinicalTrials.gov Identifier) \\
\hline 1 & Convalescent Plasma & Interventional (Phase 1) & Treatment & 20 & Hospital San Jose Tec de Monterrey (NCT04333355) \\
\hline 2 & Anti-SARS-CoV-2 convalescent plasma & Interventional (Early Phase 1) & Treatment & 20 & Orthosera Kft. (NCT04345679) \\
\hline 3 & Convalescent Plasma Transfusion & Interventional (Phase 2) & Treatment & 20 & Institute of Liver and Biliary Sciences, India (NCT04346446) \\
\hline 4 & Convalescent Plasma & Interventional (Phase 2) & Treatment & 15 & Saint Francis Care (NCT04343261 \\
\hline 5 & COVID-19 convalescent plasma & Expanded Access & Treatment & Expanded Access & Mayo Clinic (NCT04338360) \\
\hline 6 & $\begin{array}{l}\text { Transfusion of COVID-19 convalescent } \\
\text { plasma }\end{array}$ & Interventional (Phase 2) & Treatment & 120 & Assistance Publique - Hôpitaux de Paris (NCT04345991) \\
\hline 7 & $\begin{array}{l}\text { convalescent plasma from recovered } \\
\text { COVID } 19 \text { donor }\end{array}$ & Interventional (Phase 2) & Treatment & 40 & King Fahad Specialist Hospital Dammam (NCT04347681) \\
\hline \multirow[t]{2}{*}{8} & Convalescent Plasma & Interventional (Phase 1/2) & Treatment & 500 & Stony Brook University (NCT04344535) \\
\hline & Standard Donor Plasma & & & & \\
\hline 9 & Convalescent Plasma & Interventional (Phase 2) & Treatment & 55 & Hackensack Meridian Health (NCT04343755) \\
\hline 10 & Convalescent Plasma & Interventional (Phase 2) & Treatment & 426 & Erasmus Medical Center (NCT04342182) \\
\hline 11 & Convalescent Plasma & Interventional (Phase 2) & Treatment & 278 & Cristina Avendaño Solá (NCT04345523) \\
\hline 12 & Convalescent Plasma & Interventional (EarlyPhase1) & Treatment & 10 & University of Chicago (NCT04340050) \\
\hline 13 & $\begin{array}{l}\text { Plasma Hydroxychloroquine } \\
\text { Azithromycin }\end{array}$ & Interventional (Phase 1/2) & Treatment & 80 & Universidad del Rosario (NCT04332835) \\
\hline 14 & Convalescent Plasma & Interventional & Treatment & 30 & Mazandaran University of Medical Sciences (NCT04327349) \\
\hline 15 & Convalescent Plasma & Observational & & 15 & Shanghai Public Health Clinical Center (NCT04292340) \\
\hline 16 & $\begin{array}{l}\text { Anti- SARS-CoV-2 Plasma } \\
\text { SARS-CoV-2 non-immune Plasma }\end{array}$ & Interventional (Phase 2) & Treatment & 150 & Johns Hopkins University (NCT04323800) \\
\hline 17 & $\begin{array}{l}\text { Convalescent anti-SARS-CoV-2 plasma } \\
\text { Sarilumab, Baricitinib, } \\
\text { Hydroxychloroquine }\end{array}$ & Interventional (Phase 3) & Treatment & 1500 & Thomas Benfield (NCT04345289) \\
\hline 18 & $\begin{array}{l}\text { high-titer anti-Sars-CoV-2 plasma, } \\
\text { oxygen therapy }\end{array}$ & Interventional (Phase 1) & Treatment & 115 & Baylor Research Institute (NCT04333251) \\
\hline 19 & $\begin{array}{l}\text { Anti-coronavirus antibodies } \\
\text { (immunoglobulins)obtained with DFPP } \\
\text { from a convalescent patient }\end{array}$ & Interventional & Treatment & 10 & A.O. Ospedale Papa Giovanni XXIII (NCT04346589 \\
\hline
\end{tabular}




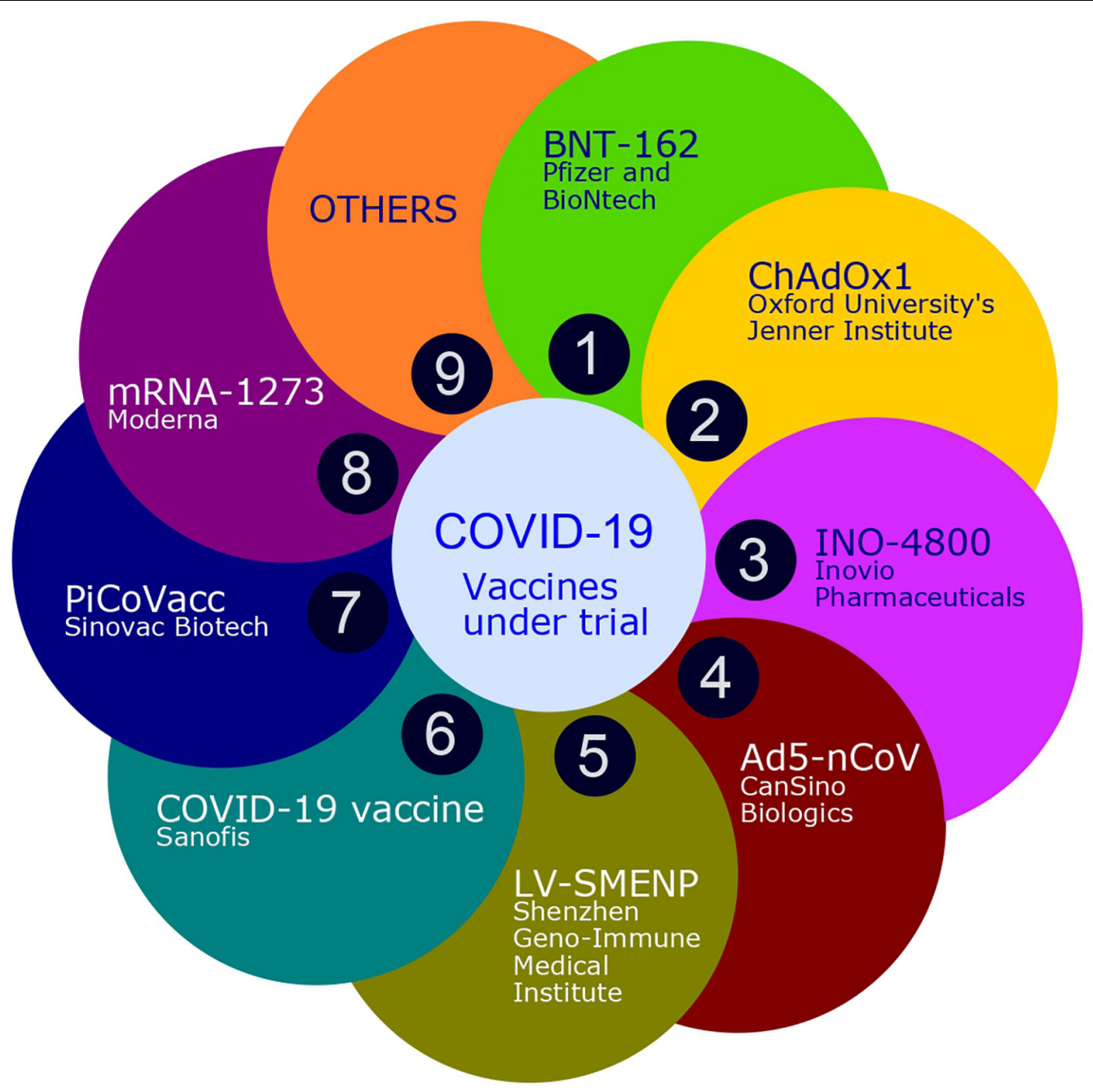

FIGURE 5 | Some of the ongoing vaccine trials in lead which are specific to COVID-19.

Several trials on the effectiveness of this agent have been found to be registered in the Chinese Clinical Trial Registry. Based on this, Liu and associates examined the antiviral action of hydroxychloroquine and chloroquine against COVID-19 in vitro. It was found that both the agents elevate the intracellular organelles' $\mathrm{pH}$, which is critical in membrane fusion. Both the drugs were able to exert their actions to inhibit the viral entry as well as at some post-entry stages. It was found that the drugs could block the transport of the virus from the early endosomes to endolysosomes, which is essential for the release of the viral genome. The study concludes that hydroxychloroquine is as effective as chloroquine for the in vitro inhibition of SARS-CoV2 infection with comparatively less toxicity (Liu J. et al., 2020). A survey in a University Hospital in Marseille reassured the disappearance or decrease of viral load in hydroxychloroquine treated patients, and the result is reinforced by concomitant use of azithromycin (Gautret et al., 2020).

Wang and associates demonstrated the effectiveness of chloroquine at entry as well as post-entry phases of COVID-19 infection in vitro cell lines. Further, the immune modulation property can induce synergism in its antiviral activity in vivo (Wang M. et al., 2020). Still, there is an opinion that the option of using chloroquine for the treatment of COVID19 should be properly analyzed in light of the new hopeful declarations, by considering the possible side effects (Colson et al., 2020; Touret and de Lamballerie, 2020). Chloroquine causes under expression of phosphatidylinositol binding clathrin assembly protein and thereby affects endocytosis (Hu et al., 2020). Meanwhile, the assessment of safety and efficiency of chloroquine for treating COVID-19 demands the need for safety data from urgent high-quality trials from various geographical areas (Cortegiani et al., 2020). Interestingly, chloroquine phosphate shortened the course of the disease in clinical trials and thus seems to be better than the control, for the inhibition of pneumonia (Gao et al., 2020) Also, in vitro study revealed that hydroxychloroquine shows the more powerful effect as compared to chloroquine (Yao et al., 2020). As of now, more than 40 clinical trials are registered to assess and/or 
compare the effectiveness and/or safety of chloroquine and hydroxychloroquine.

\section{Metronidazole}

Metronidazole is another nucleic acid synthesis inhibitor and a potential candidate which can counter most of the immunopathological symptoms of SARS-CoV-2 infection. In vitro as well as in vivo studies proved that this drug could reduce cytokine levels, which are generally increased during this disease. In vitro studies proved that metronidazole at high doses had a marked inhibitory effect on lymphoproliferative assay (Fararjeh et al., 2008; Rizzo et al., 2010). Also, it can reduce neutrophil-generated ROS in the event of inflammation. But studies with a big number of groups are needed to prove its effectiveness (Gharebaghi et al., 2020)

Sofosbuvir, an FDA approved nucleotide polymerase inhibitor mainly used for the management of hepatitis $C$ is under test by a Chinese research foundation (Vellingiri et al., 2020). Previously sofosbuvir was used along with ribavirin and interferon. The use of sofosbuvir is reported in the management of the Zika virus also (Cheema et al., 2019).

\section{Some Other Potential Agents}

Baricitinib, carfilzomib, indinavir, baloxavir, ruxolitinib, fedratinib, and azvudine are some other potential agents to treat this respiratory disease (Peter et al., 2020). Among these, fedratinib, baricitinib, and ruxolitinib are potent antiinflammatory agents and powerful Janus kinase inhibitors (Stebbing et al., 2020) which are approved for rheumatoid arthritis and myelofibrosis. It is reported that these drugs are effective to control the increased levels of cytokines usually observed in COVID-19 patients (Stebbing et al., 2020). Twelve clinical trials have been registered to evaluate the efficacy and safety of ruxolitinib in COVID-19 patients. Baricitinib is not considered an ideal choice for the treatment of COVID-19, since it may enhance the chance of co-infection and increase the incidence of anemia (Praveen et al., 2020). Eight clinical trials are registered for the evaluation of the efficacy of baricitinib in COVID-19 patients. The immune-modulating and anti-inflammatory agents are not usually recommended in pneumonia associated with COVID-19. Nevertheless, as per the pathology of pulmonary edema as well as the formation of hyaline membrane, it could be reasonably assumed that well-timed and appropriate therapy with immunomodulators along with other supportive measures may save the COVID19 patients from ARDS. Based on these considerations, one clinical trial is going on for the evaluation of fingolimod, an immunology modulator generally used in multiple sclerosis (ClinicalTrails, 2020).

Nitazoxanide is an antiprotozoal drug with a broad-spectrum antiviral activity, which can also reduce the production of proinflammatory cytokines (Kelleni, 2020). With regard to this feature, it has been registered for studies in more than 6 clinical trials as monotherapy or as combination therapy for the management of COVID-19 (ClinicalTrails, 2020).

Severe acute respiratory syndrome coronavirus-2 infection depends on ACE2 and TMPRSS2 proteins on the host cell surface and these can be blocked by protease inhibitors (Nadeem et al., 2020). Camostat mesylate is a synthetic serine protease inhibitor that can inhibit TMPRSS2 protein in lung cells (Hoffmann et al., 2020; McKee et al., 2020). Nafamostat mesylate, another TMPRSS2 serine protease inhibitor, may also prevent the entry of virus into the host cell. Cell culture experiments proved that nafamostat mesylate inhibited SARS-CoV-2 infection in SARS-CoV-2 infected Vero E6 cells $\left(\mathrm{EC}_{50}=22.5 \mu \mathrm{M}\right)$ (Wang M. et al., 2020). There are numerous similarities in clinical, pathological, and laboratory findings of moderate to severe SARS-CoV-2 infection and haemophagocytic lymphohistiocytosis. The possibility of etoposide may be considered for treating haemophagocytic lymphohistiocytosis associated with moderately severe or severe forms of SARSCoV-2 infection (Hamizi et al., 2020). The viroporine channel of COVID-19 can be effectively blocked by amantadine and thus can prevent viral genome release into the cytoplasm. Therefore, amantadine can be used to mitigate the effects of COVID-19 if used in an early stage of infection (Abreu et al., 2020). Niclosamide is another potential option since it can block endocytosis and autophagy of SARS-CoV-2 (Pindiprolu and Pindiprolu, 2020).

Drug repurposing approach by in silico studies will give potential clues about the agents which might be helpful to fight this deadly virus. It was found that lopinavir, galidesivir, asunaprevir, CGP42112A, remdesivir, indinavir, ABT450, ritonavir, and methisazone can interact with more than two protein structures of COVID-19. Among these, HIV protease inhibitors exhibited excellent outcomes in docking studies (Shah et al., 2020). Similarly, Wu and associates carried out an analysis by computational methods for discovering therapeutic targets of novel coronavirus as well as predicting potential medicines. The study reports more than 50 natural compounds and more than 50 drugs which may be considered for further studies for the treatment of COVID 19 (Wu et al., 2020). In a study using the drug-target interaction model, atazanavir, remdesivir, efavirenz, ritonavir, dolutegravir, lopinavir, darunavir showed good inhibitory potency, with atazanavir in the first position, followed by remdesivir (Beck et al., 2020). When docking was performed with solvent molecular dynamics on several natural compounds, compounds like 5,7,3','-Tetrahydroxy-2'-(3,3-dimethylallyl) isoflavone, myricitrin, and methyl rosmarinate were observed to be the most promising agents against COVID-19 (ul Qamar et al., 2020). Muralidharan et al. conducted computational studies to understand the synergism of lopinavir, ritonavir, and oseltamivir. They found that the combination of these three drugs resulted in superior binding energy as compared to the individual agents (Muralidharan et al., 2020).

Based on Feline Infectious Peritonitis Strategies, Olsen et al. (2020) suggested the use of nelfinavir and amodiaquine for the treatment of SARS-CoV-2 infection with a potential CNS invasion. In vitro study in Vero-E6 cells showed that remdesivir and lopinavir inhibit the replication of SARS-CoV-2 with EC50 at 23.15 and $26.63 \mu \mathrm{M}$ concentrations, respectively. At the same time, homoharringtonine and emetine have EC50 values of 2.55 and $0.46 \mu \mathrm{M}$, respectively, for the inhibition of SARS-CoV-2 replication. In addition, a synergistic effect 
for the combination of remdesivir and emetine has been also observed (Choy et al., 2020). It may be noted that a 60-year-old immunocompromised female cancer patient on darunavir/cobicistat along with hydroxychloroquine was able to leave the hospital within six days, which shows the potential of darunavir/cobicistat even in immunocompromised patients (Spezzani et al., 2020).

RAC/CDC42-activated kinases (PAK1) are required for the pathogenic process of different kinds of viruses including SARSCoV-2. Therefore, PAK1 blockers like melatonin, propolis, cicloresonide, some anti-malaria drugs like ivermectin, and ketorolac could act as promising agents against COVID-19 (Maruta and $\mathrm{He}, 2020$ ). Ivermectin is a broad-spectrum antiparasitic agent approved by the FDA. An in vitro study demonstrated that it can cause a 5000 times decrease in SARSCoV-2 viral RNA in $48 \mathrm{~h}$ and it needs further investigation and clinical trials as a promising therapeutic agent against COVID19 (Caly et al., 2020). This study received wide attention which finally led USFDA to issue a letter clarifying that the study tested ivermectin neither in humans or animals. The letter also warned the use of ivermectin containing veterinary products in humans (FDA, 2020). The mechanism of action and dose of some potential drugs against COVID-19 are given in Table 4 .

\section{PERSPECTIVES}

Hopefully, several perspectives and hypotheses are available related to the treatment and prophylaxis against COVID-19.
Some of them appear interesting and promising for further consideration and studies. In such a perspective, it is mentioned that ATP has a crucial role in cellular function and cyclic ATP depletion can cause cellular dysfunction including immune cells. ATP-repletion can prevent the "cytokine storm" in COVID19 and increase the cellular energy to fight against the virus (Taghizadeh-Hesary and Akbari, 2020). Other than the antiviral activity chloroquine/hydroxychloroquine cause the movement of extracellular zinc into intracellular lysosomes and thus hinders the enzyme RNA polymerase which is required for viral replication. Zinc deficiency is commonly seen in geriatrics and also in patients with diabetes, chronic pulmonary disease, cardiovascular diseases, etc. Therefore, zinc supplementation along with chloroquine therapy may reduce the mortality and morbidity rate in COVID-19 (Derwand and Scholz, 2020). Copper is a very important micronutrient required for the functioning of vital immune cells like B cells, helper $\mathrm{T}$ cells, natural killer cells, macrophages, etc. Therefore, enhancement of plasma level of copper may boost the immune system and may act as a preventive or therapeutic measure against COVID-19 (Raha et al., 2020). If COVID-19 results in long term cardiopulmonary damage, cardiopulmonary rehabilitation is required; exercise can be considered as a therapy of choice. Since physical movement of many people has become less in this pandemic situation, therefore exercise should be given prime importance. It is proposed that exercise may help in lowering the risk of SARS-CoV-2 infection by minimizing cardiopulmonary sequel in the recovery period (Heffernan and Young Jae, 2020). In a hypothesis, it is postulated that the

TABLE 4 | The mechanism of action and dose of potential drugs against COVID-19.

\begin{tabular}{|c|c|c|}
\hline Drug & Mechanism of action & Dose \\
\hline $\begin{array}{l}\text { Chloroquine/ } \\
\text { Hydroxychloroquine }\end{array}$ & $\begin{array}{l}\text { Modify the transcription process and signaling } \\
\text { pathways }\end{array}$ & $\begin{array}{l}400 \mathrm{mg} \text { two times on the first day, then } 200 \mathrm{mg} \text { two times } \\
\text { up to } 7 \text { days }\end{array}$ \\
\hline Umifenovir & Inhibition of membrane fusion & $200 \mathrm{mg}$ three times daily maximum up to 10 days \\
\hline Lopinavir/Ritonavir & Protease inhibitor & $400 / 100 \mathrm{mg}$ two times a day for 14 days \\
\hline Favipiravir & Inhibits viral replication & $\begin{array}{l}1600 \mathrm{mg} \text { two times in the first day, then } 600 \mathrm{mg} \text { two times } \\
\text { per day up to } 6 \text { days }\end{array}$ \\
\hline Ribavirin & Nucleoside inhibitor & $\begin{array}{l}500 \mathrm{mg} \text { two or three times daily along with interferon } \alpha \text { or } \\
\text { lopinavir/ritonavir maximum up to } 10 \text { days }\end{array}$ \\
\hline Metronidazole & Nucleic acid synthesis inhibitor & $400 \mathrm{mg}$ two times daily maximum up to 14 days \\
\hline Baricitinib & Anti-Janus kinase inhibitor & $4 \mathrm{mg} /$ day for two weeks \\
\hline Camostat Mesilate & Block cell entry (Serine protease inhibitor) & $200 \mathrm{mg}$ three times daily for 5 days \\
\hline IFN $\alpha$ & Inhibition of viral replication & $\begin{array}{l}\text { atomization: } 45 \mu \mathrm{g} \text {, two times daily for two weeks or } 5 \\
\text { million units or equivalent dose, twice daily not more than } \\
10 \text { days }\end{array}$ \\
\hline Fingolimod & Immunology modulator & $0.5 \mathrm{mg}$ per day orally for 3 days \\
\hline Ruxolitinib & JAK1 and JAK2 inhibitor & $\begin{array}{l}10 \mathrm{mg} \text { two times a day for } 14 \text { days with dose reduction or } \\
\text { escalation }\end{array}$ \\
\hline Tocilizumab & IL-6 blocker & $8 \mathrm{mg} / \mathrm{kg}$ \\
\hline
\end{tabular}


immunologic effect and enhancement of antibody production by diethylcarbamazine could confer its anti-COVID-19 effect. Diethylcarbamazine is expected to show the immunologic effects by the inhibition of lipoxygenase (LOX) and cyclooxygenase (COX) enzymes (Abeygunasekera and Jayasinghe, 2020). In a similar hypothesis, montelukast is suggested to be useful in restraining the progression of the disease. The anti-inflammatory effect, suppression of oxidative stress, and reduced cytokine production are supposed to facilitate the effect (Fidan and Aydoğdu, 2020). Clinical researches proved the benefit of surfactant treatment in patients with ARDS (Walmrath et al., 1996).Also it was found that early administration of natural lung surfactants can improve the pulmonary function in adult patients with severe respiratory distress syndrome (Mirastschijski et al., 2020). Surfactant based prophylactic management as well as therapy can be considered as another promising strategy (Pramod et al., 2020).

\section{CONCLUSION}

This review provides an overview of the current treatment strategies, ongoing clinical trials, and potential future options based on published research and registered clinical trials related to the COVID-19. The basics of SARS-CoV-2, the virus, and COVID-19, the disease, are provided. It was noted that none of the present therapies or strategies could be an absolute solution to end this pandemic. The drugs which have a repurposing option are selected based on its activity against RNA viruses like SARS$\mathrm{CoV}$, MERS-CoV, influenza virus, and Ebola virus. The hope of

\section{REFERENCES}

Abeygunasekera, A., and Jayasinghe, S. (2020). Is the anti-filarial drug diethylcarbamazine useful to treat COVID-19? Med. Hypotheses 143:109843. doi: 10.1016/j.mehy.2020.109843

Abreu, G. E. A., Aguilar, M. E. H., Covarrubias, D. H., and Durán, F. R. (2020). Amantadine as a drug to mitigate the effects of COVID-19. Med. Hypotheses 140:109755. doi: 10.1016/j.mehy.2020.109755

Ahn, J. Y., Sohn, Y., Lee, S. H., Cho, Y., Hyun, J. H., Baek, Y. J., et al. (2020). Use of convalescent plasma therapy in two COVID-19 patients with acute respiratory distress syndrome in Korea. J. Korean Med. Sci. 35:e149.

Bachanova, V., Bishop, M. R., Dahi, P., Dholaria, B., Grupp, S. A., Hayes-Lattin, B., et al. (2020). CAR T cell therapy during the COVID-19 Pandemic. Biol. Blood Marrow Transplant. J. Am. Soc. Blood Marrow Transplant. 26, 1239-1246.

Bakhtawar, N., Usman, M., and Khan, M. M. U. (2020). Convalescent plasma therapy and its effects on COVID-19 patient outcomes: a systematic review of current literature. Cureus 12:e9535.

Bassetti, M., Vena, A., and Giacobbe, D. R. (2020). The novel Chinese coronavirus (2019-nCoV) infections: challenges for fighting the storm. Eur. J. Clin. Invest. 50:e13209.

Beck, B. R., Shin, B., Choi, Y., Park, S., and Kang, K. (2020). Predicting commercially available antiviral drugs that may act on the novel coronavirus (SARS-CoV-2) through a drug-target interaction deep learning model. Comput. Struct. Biotechnol. J. 18, 784-790. doi: 10.1016/j.csbj.2020. 03.025

Bennardo, F., Buffone, C., and Giudice, A. (2020). New therapeutic opportunities for COVID-19 patients with Tocilizumab: possible correlation of interleukin6 receptor inhibitors with osteonecrosis of the jaws. Oral Oncol. 106:104659. doi: 10.1016/j.oraloncology.2020.104659 the successful vaccine, other immunological products, and cellbased therapeutics is still alive. Convalescent plasma therapy is successful in some cases. At present, it could be seen that none of the presently available approaches or drugs was able to stop this pandemic. The results of many clinical trials are yet to be announced. Further, the suggested future potential solutions seem to be promising to end this pandemic.

\section{AUTHOR CONTRIBUTIONS}

SK: conceptualization, writing - original draft, and funding acquisition. HA: supervision, writing - review and editing. SB-E: writing - review and editing. NA: supervision, writing - review and editing. SM: writing - review and editing. AN: writing review and editing. PD: writing - review and editing. All authors contributed to the article and approved the submitted version.

\section{FUNDING}

This project was funded by the Deanship of Scientific Research (DSR) at King Abdulaziz University, Jeddah, under grant no. GCV19-25-1441.

\section{ACKNOWLEDGMENTS}

We therefore, acknowledge with thanks DSR for technical and financial support.

Bersanelli, M. (2020). Controversies about COVID-19 and anticancer treatment with immune checkpoint inhibitors. Immunotherapy 12, 269-273. doi: 10.2217/ imt-2020-0067

Bhatnagar, T., Murhekar, M. V., Soneja, M., Gupta, N., Giri, S., Wig, N., et al. (2020). Lopinavir/ritonavir combination therapy amongst symptomatic coronavirus disease 2019 patients in India: Protocol for restricted public health emergency use. Indian J. Med. Res. 151, 184-189.

Blaising, J., Polyak, S. J., and Pécheur, E. I. (2014). Arbidol as a broad-spectrum antiviral: An update. Antiviral Res. 107, 84-94. doi: 10.1016/j.antiviral.2014.04. 006

Bloch, E. M., Shoham, S., Casadevall, A., Sachais, B. S., Shaz, B., Winters, J. L., et al. (2020). Deployment of convalescent plasma for the prevention and treatment of COVID-19. J. Clin. Invest. 130, 2757-2765.

Bogoch, I. I., Watts, A., Thomas-Bachli, A., Huber, C., Kraemer, M. U. G., and Khan, K. (2020). Pneumonia of unknown aetiology in Wuhan, China: potential for international spread via commercial air travel. J. Travel Med. 27:taaa008.

Borah, P., Deb, P. K., Deka, S., Venugopala, K. N., Singh, V., Mailavaram, R. P., et al. (2020). Current scenario and future prospect in the management of COVID-19. Curr. Med. Chem. 27, 1-23.

Buonaguro, F. M., Puzanov, I., and Ascierto, P. A. (2020). Anti-IL6R role in treatment of COVID-19-related ARDS. J. Transl. Med. 18:165.

Caly, L., Druce, J. D., Catton, M. G., Jans, D. A., and Wagstaff, K. M. (2020). The FDA-approved drug ivermectin inhibits the replication of SARS-CoV-2 in vitro. Antiviral Res. 178:104787. doi: 10.1016/j.antiviral.2020.104787

Cao, B., Wang, Y., Wen, D., Liu, W., Wang, J., Fan, G., et al. (2020). A trial of lopinavir-ritonavir in adults hospitalized with severe covid-19. N. Engl. J. Med. 382, 1787-1799.

Cellina, M., Orsi, M., Bombaci, F., Sala, M., Marino, P., and Oliva, G. (2020). Favorable changes of CT findings in a patient with COVID-19 pneumonia 
after treatment with tocilizumab. Diagn. Interv. Imaging 101, 323-324. doi: 10.1016/j.diii.2020.03.010

Ceribelli, A., Motta, F., De Santis, M., Ansari, A. A., Ridgway, W. M., Gershwin, M. E., et al. (2020). Recommendations for coronavirus infection in rheumatic diseases treated with biologic therapy. J. Autoimmun. 109:102442. doi: 10.1016/ j.jaut.2020.102442

Chavez, S., Long, B., Koyfman, A., and Liang, S. Y. (in press). Coronavirus disease (COVID-19): a primer for emergency physicians. Am. J. Emerg. Med. doi: 10.1016/j.jaut.2020.102442

Cheema, S. U. R., Rehman, M. S., Hussain, G., Cheema, S. S., and Gilani, N. (2019). Efficacy and tolerability of sofosbuvir and daclatasvir for treatment of hepatitis $\mathrm{C}$ genotype $1 \& 3$ in patients undergoing hemodialysis- a prospective interventional clinical trial. BMC Nephrol. 20:438.

Chen, D., Xu, W., Lei, Z., Huang, Z., Liu, J., Gao, Z., et al. (2020). Recurrence of positive SARS-CoV-2 RNA in COVID-19: a case report. Int. J. Infect. Dis. 93, 297-299. doi: 10.1016/j.ijid.2020.03.003

Chen, L., Xiong, J., Bao, L., and Shi, Y. (2020). Convalescent plasma as a potential therapy for COVID-19. Lancet Infect. Dis. 20, 398-400. doi: 10.1016/s14733099(20)30141-9

Cheng, R. Z. (2020). Can early and high intravenous dose of vitamin C prevent and treat coronavirus disease 2019 (COVID-19)? Med. Drug Discov. 5:100028. doi: 10.1016/j.medidd.2020.100028

Cheng, Y., Wong, R., Soo, Y. O. Y., Wong, W. S., Lee, C. K., Ng, M. H. L., et al. (2005). Use of convalescent plasma therapy in SARS patients in Hong Kong. Eur. J. Clin. Microbiol. Infect. Dis. 24, 44-46. doi: 10.1007/s10096-004-1271-9

Choy, K.-T., Wong, A. Y.-L., Kaewpreedee, P., Sia, S. F., Chen, D., Hui, K. P. Y., et al. (2020). Remdesivir, lopinavir, emetine, and homoharringtonine inhibit SARS-CoV-2 replication in vitro. Antiviral Res. 178:104786. doi: 10.1016/j. antiviral.2020.104786

ClinicalTrails (2020). Home-ClinicalTrials.gov. Available online at: https:// clinicaltrials.gov/ct2/home (accessed March 31, 2020).

Colson, P., Rolain, J. M., and Raoult, D. (2020). Chloroquine for the 2019 novel coronavirus SARS-CoV-2. Int. J. Antimicrob. Agents 55:105923. doi: 10.1016/j. ijantimicag.2020.105923

Cooper, C. L., van Heeswijk, R. P. G., Gallicano, K., Cameron, D. W., and Review, A. (2003). of low-dose ritonavir in protease inhibitor combination therapy. Clin. Infect. Dis. 36, 1585-1592. doi: 10.1086/375233

Coperchini, F., Chiovato, L., Croce, L., Magri, F., and Rotondi, M. (2020). The Cytokine storm in COVID-19: an overview of the involvement of the chemokine/chemokine-receptor system. Cytokine Growth Factor Rev. 53, 2532. doi: 10.1016/j.cytogfr.2020.05.003

Cortegiani, A., Ingoglia, G., Ippolito, M., Giarratano, A., and Einav, S. (2020). A systematic review on the efficacy and safety of chloroquine for the treatment of COVID-19. J. Crit. Care 57, 279-283.

Costanzo, M., De Giglio, M. A. R., and Roviello, G. N. (2020). SARS CoV-2: recent reports on antiviral therapies based on lopinavir/ritonavir, darunavir/umifenovir, hydroxychloroquine, remdesivir, favipiravir and other drugs for the treatment of the new coronavirus. Curr. Med. Chem. 27, 45364541. doi: 10.2174/0929867327666200416131117

de Alwis, R., Chen, S., Gan, E. S., and Ooi, E. E. (2020). Impact of immune enhancement on Covid-19 polyclonal hyperimmune globulin therapy and vaccine development. EBioMedicine 55:102768. doi: 10.1016/j.ebiom.2020. 102768

De Wit, E., Feldmann, F., Cronin, J., Jordan, R., Okumura, A., Thomas, T., et al. (2020). Prophylactic and therapeutic remdesivir (GS-5734) treatment in the rhesus macaque model of MERS-CoV infection. Proc. Natl. Acad. Sci. U.S.A. 117, 6771-6776. doi: 10.1073/pnas.1922083117

De Wit, E., Van Doremalen, N., Falzarano, D., and Munster, V. J. (2016). SARS and MERS: Recent insights into emerging coronaviruses. Nat. Rev. Microbiol. 14, 523-534. doi: 10.1038/nrmicro.2016.81

Deng, L., Li, C., Zeng, Q., Liu, X., Li, X., Zhang, H., et al. (2020). Arbidol combined with $\mathrm{LPV} / \mathrm{r}$ versus LPV/r alone against corona virus disease 2019: 81, e1-e5 A retrospective cohort study. J. Infect. 81, E1-E5.

Derwand, R., and Scholz, M. (2020). Does zinc supplementation enhance the clinical efficacy of chloroquine/hydroxychloroquine to win todays battle against COVID-19? Med. Hypotheses 142:109815. doi: 10.1016/j.mehy.2020.109815

Devaux, C. A., Rolain, J.-M., Colson, P., and Raoult, D. (2020). New insights on the antiviral effects of chloroquine against coronavirus: what to expect for
COVID-19? Int. J. Antimicrob. Agents 55:105938. doi: 10.1016/j.ijantimicag. 2020.105938

Ding, Q., Lu, P., Fan, Y., Xia, Y., and Liu, M. (2020). The clinical characteristics of pneumonia patients coinfected with 2019 novel coronavirus and influenza virus in Wuhan, China. J. Med. Virol. 92, 1549-1555. doi: 10.1002/jmv.25781

Dong, D., Tang, Z., Wang, S., Hui, H., Gong, L., Lu, Y., et al. (2020). The role of imaging in the detection and management of COVID-19: a review. IEEE Rev. Biomed. Eng. doi: 10.1109/RBME.2020.2990959. [Epub ahead of print].

Dong, L., Hu, S., and Gao, J. (2020). Discovering drugs to treat coronavirus disease 2019 (COVID-19). Drug Discov. Ther. 14, 58-60. doi: 10.5582/ddt.2020.01012

Du, B., Qiu, H. B., Zhan, X., Wang, Y. S., Kang, H. Y. J., Li, X. Y., et al. (2020). Pharmacotherapeutics for the new coronavirus pneumonia. Chinese J. Tuberc. Respir. Dis. 43:E012.

Du, Y.-X., and Chen, X.-P. (2020). Favipiravir: pharmacokinetics and concerns about clinical trials for 2019-nCoV infection. Clin. Pharmacol. Ther. 108:188.

Duan, K., Liu, B., Li, C., Zhang, H., Yu, T., Qu, J., et al. (2020). Effectiveness of convalescent plasma therapy in severe COVID-19 patients. Proc. Natl. Acad. Sci. U.S.A. 117, 9490-9496.

Ekins, S., Mottin, M., Ramos, P. R. P. S., Sousa, B. K. P., Neves, B. J., Foil, D. H., et al. (2020). Déjà vu: stimulating open drug discovery for SARS-CoV-2. Drug Discov. Today 25, 928-941. doi: 10.1016/j.drudis.2020.03.019

Elfiky, A. A. (2020). Ribavirin, remdesivir, sofosbuvir, galidesivir, and tenofovir against SARS-CoV-2 RNA dependent RNA polymerase (RdRp): A molecular docking study. Life Sci. 253:117592. doi: 10.1016/j.lfs.2020.117592

Fararjeh, M., Mohammad, M. K., Bustanji, Y., AlKhatib, H., and Abdalla, S. (2008). Evaluation of immunosuppression induced by metronidazole in Balb/c mice and human peripheral blood lymphocytes. Int. Immunopharmacol. 8, 341-350. doi: 10.1016/j.intimp.2007.10.018

FDA (2020). FDA Letter to Stakeholders: Do Not Use Ivermectin Intended for Animals as Treatment for COVID-19 in Humans | FDA. Available online at: https://www.fda.gov/animal-veterinary/product-safety-information/fdaletter-stakeholders-do-not-use-ivermectin-intended-animals-treatmentcovid-19-humans (accessed May 17, 2020).

Fidan, C., and Aydoğdu, A. (2020). As a potential treatment of COVID-19: montelukast. Med. Hypotheses 142:109828. doi: 10.1016/j.mehy.2020.109828

Fu, B., Xu, X., and Wei, H. (2020). Why tocilizumab could be an effective treatment for severe COVID-19? J. Transl. Med. 18:164.

Gao, J., Tian, Z., and Yang, X. (2020). Breakthrough: chloroquine phosphate has shown apparent efficacy in treatment of COVID-19 associated pneumonia in clinical studies. Biosci. Trends 14, 72-73. doi: 10.5582/bst.2020. 01047

Gautret, P., Lagier, J.-C., Parola, P., Hoang, V. T., Meddeb, L., Mailhe, M., et al. (2020). Hydroxychloroquine and azithromycin as a treatment of COVID-19: results of an open-label non-randomized clinical trial. Int. J. Antimicrob. Agents 56:105949. doi: 10.1016/j.ijantimicag.2020.105949

Gavriatopoulou, M., Korompoki, E., Fotiou, D., Ntanasis-Stathopoulos, I., Psaltopoulou, T., Kastritis, E., et al. (2020). Organ-specific manifestations of COVID-19 infection. Clin. Exp. Med. 20, 493-506. doi: 10.1007/s10238-02000648-x

Gay, B., Bernard, E., Solignat, M., Chazal, N., Devaux, C., Briant, L., et al. (2012). entry of chikungunya virus into Aedes albopictus cells. Infect. Genet. Evol. 12, 1275-1281. doi: 10.1016/j.meegid.2012.02.003

Gharebaghi, R., Heidary, F., Moradi, M., and Parvizi, M. (2020). Metronidazole; a potential novel addition to the COVID-19 treatment regimen. Arch. Acad. Emerg. Med. 8:e40.

Gordon, C. J., Tchesnokov, E. P., Feng, J. Y., Porter, D. P., and Götte, M. (2020). The antiviral compound remdesivir potently inhibits RNA-dependent RNA polymerase from Middle East respiratory syndrome coronavirus. J. Biol. Chem. 15, 4773-4779. doi: 10.1074/jbc.ac120.013056

Graham Carlos, W., Dela Cruz, C. S., Cao, B., Pasnick, S., and Jamil, S. (2020). Novel Wuhan (2019-NCoV) coronavirus. Am. J. Respir. Crit. Care Med. 201, $7-8$.

Hamizi, K., Aouidane, S., and Belaaloui, G. (2020). Etoposid-based therapy for severe forms of COVID-19. Med. Hypotheses 142:109826. doi: 10.1016/j.mehy. 2020.109826

Heffernan, K. S., and Young Jae, S. (2020). Exercise as medicine for COVID-19: an ACE in the hole? Med. Hypotheses 142:109835. doi: 10.1016/j.mehy.2020. 109835 
Helmy, Y. A., Fawzy, M., Elaswad, A., Sobieh, A., Kenney, S. P., and Shehata, A. A. (2020). The COVID-19 pandemic: a comprehensive review of taxonomy, genetics, epidemiology, diagnosis, treatment, and control. J. Clin. Med. 9:1225. doi: $10.3390 /$ jcm 9041225

Hoffmann, M., Kleine-Weber, H., Schroeder, S., Krüger, N., Herrler, T., Erichsen, S., et al. (2020). SARS-CoV-2 cell entry depends on ACE2 and TMPRSS2 and is blocked by a clinically proven protease inhibitor. Cell 181, 271-280.e8.

Holshue, M. L., DeBolt, C., Lindquist, S., Lofy, K. H., Wiesman, J., Bruce, H., et al. (2020). First case of 2019 novel coronavirus in the United States. N. Engl. J. Med. 382, 929-936.

$\mathrm{Hu}, \mathrm{T}$. Y., Frieman, M., and Wolfram, J. (2020). Insights from nanomedicine into chloroquine efficacy against COVID-19. Nat. Nanotechnol. 15, 247-249. doi: 10.1038/s41565-020-0674-9

Huang, C., Wang, Y., Li, X., Ren, L., Zhao, J., Hu, Y., et al. (2020). Clinical features of patients infected with 2019 novel coronavirus in Wuhan. China. Lancet 395 , 497-506.

Jean, S.-S., Lee, P.-I., and Hsueh, P.-R. (2020). Treatment options for COVID19: the reality and challenges. J. Microbiol. Immunol. Infect. 53, 436-443. doi: 10.1016/j.jmii.2020.03.034

Ji, W., Wang, W., Zhao, X., Zai, J., and Li, X. (2020). Cross-species transmission of the newly identified coronavirus 2019-nCoV. J. Med. Virol. 92, 433-440. doi: 10.1002/jmv.25682

Kandeel, M., and Al-Nazawi, M. (2020). Virtual screening and repurposing of FDA approved drugs against COVID-19 main protease. Life Sci. 251:117627. doi: 10.1016/j.lfs.2020.117627

Kelleni, M. T. (2020). Nitazoxanide/azithromycin combination for COVID-19: A suggested new protocol for early management. Pharmacol. Res. 157:104874. doi: 10.1016/j.phrs.2020.104874

Khoury, M., Rocco, P. R. M., Phinney, D. G., Krampera, M., Martin, I., Viswanathan, S., et al. (2020). Cell-based therapies for COVID-19: proper clinical investigations are essential. Cytotherapy 22, 602-605. doi: 10.1016/j. jcyt.2020.04.089

Kim, U. J., Won, E.-J., Kee, S.-J., Jung, S.-I., and Jang, H.-C. (2016). Combination therapy with lopinavir/ritonavir, ribavirin and interferon- $\alpha$ for Middle East respiratory syndrome. Antivir. Ther. 21, 455-459. doi: 10.3851/imp3002

Kodaz, H. (2020). EDITORIAL: successful treatment strategy of Turkey against covid-19 outbreak. Eurasian J. Med. Oncol. 4, 177-178.

Kumar, S., Zhi, K., Mukherji, A., and Gerth, K. (2020). Repurposing antiviral protease inhibitors using extracellular vesicles for potential therapy of COVID19. Viruses 12:486. doi: $10.3390 / \mathrm{v} 12050486$

Kupferschmidt, K., and Cohen, J. (2020). Race to find COVID-19 treatments accelerates. Science (80) 367, 1412-1413. doi: 10.1126/science.367.6485.1412

Kutlu, Ö, and Metin, A. (2020). A case of exacerbation of psoriasis after oseltamivir and hydroxychloroquine in a patient with COVID-19: Will cases of psoriasis increase after COVID-19 pandemic? Dermatol. Ther. 33:e13383.

Ledford, H. (2020). Hopes rise for coronavirus drug remdesivir. Nature doi: 10. 1038/d41586-020-01295-8. [Epub ahead of print].

Lei, J., Li, J., Li, X., and Qi, X. (2020). CT imaging of the 2019 novel coronavirus (2019-NCoV) pneumonia. Radiology 295:18. doi: 10.1148/radiol.2020200236

Leng, Z., Hou, W., Feng, Y., Yang, Y., Han, Q., and Shan, G. (2020). Transplantation of ACE2- mesenchymal stem cells improves the outcome of patients with COVID-19 pneumonia. Aging Dis. 11, 216-228. doi: 10.14336/ad.2020. 0228

Li, H., Liu, S.-M., Yu, X.-H., Tang, S.-L., and Tang, C.-K. (2020). Coronavirus disease 2019 (COVID-19): current status and future perspectives. Int. J. Antimicrob. Agents 55:105951.

Li, L., Li, Y., Zhang, L., and Hou, T. (2012). Theoretical studies on the susceptibility of oseltamivir against variants of 2009 A/H1N1 influenza neuraminidase. J. Chem. Inf. Model. 52, 2715-2729. doi: 10.1021/ci300375k

Li, Q., Guan, X., Wu, P., Wang, X., Zhou, L., Tong, Y., et al. (2020). Early transmission dynamics in Wuhan, China, of novel coronavirus-infected pneumonia. N. Engl. J. Med. 382, 1199-1207.

Li, X., Geng, M., Peng, Y., Meng, L., and Lu, S. (2020). Molecular immune pathogenesis and diagnosis of COVID-19. J. Pharm. Anal. 10, 102-108. doi: 10.1016/j.jpha.2020.03.001

Liang, B., Chen, J., Li, T., Wu, H., Yang, W., Li, Y., et al. (2020). Clinical remission of a critically ill COVID-19 patient treated by human umbilical cord mesenchymal stem cells. Medicine 99:e21429. doi: 10.1097/md.0000000000021429
Lim, J., Jeon, S., Shin, H. Y., Kim, M. J., Seong, Y. M., Lee, W. J., et al. (2020). Case of the index patient who caused tertiary transmission of COVID-19 infection in Korea: the application of lopinavir/ritonavir for the treatment of COVID19 infected pneumonia monitored by quantitative RT-PCR. J. Korean Med. Sci. 35:e79.

Liu, B., Li, M., Zhou, Z., Guan, X., and Xiang, Y. (2020). Can we use interleukin6 (IL-6) blockade for coronavirus disease 2019 (COVID-19)-induced cytokine release syndrome (CRS)? J. Autoimmun. 111:102452. doi: 10.1016/j.jaut.2020. 102452

Liu, J., Cao, R., Xu, M., Wang, X., Zhang, H., Hu, H., et al. (2020). Hydroxychloroquine, a less toxic derivative of chloroquine, is effective in inhibiting SARS-CoV-2 infection in vitro. Cell Discov. 6:16.

Lombardy Section Italian Society Infectious And Tropical Diseases (2020). Vademecum for the treatment of people with COVID-19. Edition 2.0, 13 March 2020. Infez Med. 28, 143-152.

Lu, H. (2020). Drug treatment options for the 2019-new coronavirus (2019-nCoV). Biosci. Trends 14, 69-71. doi: 10.5582/bst.2020.01020

Lu, H., Stratton, C. W., and Tang, Y. W. (2020). Outbreak of pneumonia of unknown etiology in Wuhan, China: the mystery and the miracle. J. Med. Virol. 92, 401-402. doi: 10.1002/jmv.25678

Lu, R., Zhao, X., Li, J., Niu, P., Yang, B., Wu, H., et al. (2020). Genomic characterisation and epidemiology of 2019 novel coronavirus: implications for virus origins and receptor binding. Lancet 395, 565-574. doi: 10.1016/s01406736(20)30251-8

Luo, A. (2020). Positive SARS-Cov-2 test in a woman with COVID-19 at 22 days after hospital discharge: a case report. J. Tradit. Chinese Med. Sci. 92, 814-818.

Luo, P., Liu, Y., Qiu, L., Liu, X., Liu, D., and Li, J. (2020). Tocilizumab treatment in COVID-19: A single center experience. J. Med. Virol. 92, 814-818. doi: 10.1002/jmv.25801

Maruta, H., and He, H. (2020). PAK1-blockers: Potential Therapeutics against COVID-19. Med. Drug Discov. 6:100039. doi: 10.1016/j.medidd.2020.100039

McCartney, D. M., and Byrne, D. G. (2020). Optimisation of Vitamin D Status for Enhanced Immuno-protection Against Covid-19. Ir. Med. J. 113:58.

McKee, D. L., Sternberg, A., Stange, U., Laufer, S., and Naujokat, C. (2020). Candidate drugs against SARS-CoV-2 and COVID-19. Pharmacol. Res. 157:104859. doi: 10.1016/j.phrs.2020.104859

Metcalfe, S. M. (2020). Mesenchymal stem cells and management of COVID-19 pneumonia. Med. Drug Discov. 5:100019. doi: 10.1016/j.medidd.2020.100019

Michot, J.-M., Albiges, L., Chaput, N., Saada, V., Pommeret, F., Griscelli, F., et al. (2020). Tocilizumab, an anti-IL6 receptor antibody, to treat Covid-19-related respiratory failure: a case report. Ann. Oncol. Off. J. Eur. Soc. Med. Oncol. 31, 961-964. doi: 10.1016/j.annonc.2020.03.300

Mihai, C., Dobrota, R., Schröder, M., Garaiman, A., Jordan, S., Becker, M. O., et al. (2020). COVID-19 in a patient with systemic sclerosis treated with tocilizumab for SSc-ILD. Ann. Rheum. Dis. 79, 668-669. doi: 10.1136/annrheumdis-2020217442

Mirastschijski, U., Dembinski, R., and Maedler, K. (2020). Lung surfactant for pulmonary barrier restoration in patients With COVID-19 pneumonia. Front. Med. 7:254.

Muralidharan, N., Sakthivel, R., Velmurugan, D., and Gromiha, M. M. (2020). Computational studies of drug repurposing and synergism of lopinavir, oseltamivir and ritonavir binding with SARS-CoV-2 Protease against COVID19. J. Biomol. Struct. Dyn. doi: 10.1080/07391102.2020.1752802. [Epub ahead of print].

Nadeem, M. S., Zamzami, M. A., Choudhry, H., Murtaza, B. N., Kazmi, I., Ahmad, H., et al. (2020). Origin, potential therapeutic targets and treatment for coronavirus disease (COVID-19). Pathog 9:307. doi: 10.3390/ pathogens 9040307

Newfield, C. (2018). New medical indications for thalidomide and its derivatives. Sci. J. Lander Coll. Arts Sci. 12:3.

Olsen, M., Cook, S. E., Huang, V., Pedersen, N., and Murphy, B. G. (2020). Perspectives: potential therapeutic options for SARS-CoV-2 patients based on feline infectious peritonitis strategies: central nervous system invasion and drug coverage. Int. J. Antimicrob. Agents 55:105964. doi: 10.1016/j.ijantimicag.2020. 105964

Peter, R., Ivan, G., Catherine, T., Dan, S., Olly, O., Anne, P., et al. (2020). Baricitinib as potential treatment for $2019-\mathrm{nCoV}$ acute respiratory disease. Lancet 395 , e30-e31. 
Pindiprolu, S. K. S. S., and Pindiprolu, S. H. (2020). Plausible mechanisms of Niclosamide as an antiviral agent against COVID-19. Med. Hypotheses 140:109765. doi: 10.1016/j.mehy.2020.109765

Pramod, K., Kotta, S., Jijith, U. S., Aravind, A., Abu Tahir, M., Manju, C. S., et al. (2020). Surfactant-based prophylaxis and therapy against COVID-19: A possibility. Med. Hypotheses 143, 110081. doi: 10.1016/j.mehy.2020.110081

Praveen, D., Puvvada, R. C., and Aanandhi, M. V. (2020). Janus kinase inhibitor baricitinib is not an ideal option for management of COVID-19. Int. J. Antimicrob. Agents 55:105967. doi: 10.1016/j.ijantimicag.2020.105967

Raha, S., Mallick, R., Basak, S., and Duttaroy, A. K. (2020). Is copper beneficial for COVID-19 patients? Med. Hypotheses 142:109814. doi: 10.1016/j.mehy.2020. 109814

Ren, L. L., Wang, Y. M., Wu, Z. Q., Xiang, Z. C., Guo, L., Xu, T., et al. (2020), Identification of a novel coronavirus causing severe pneumonia in human: a descriptive study. Chin. Med. J. (Engl). 133, 1015-1024.

Rizzo, A., Paolillo, R., Guida, L., Annunziata, M., Bevilacqua, N., and Tufano, M. A. (2010). Effect of metronidazole and modulation of cytokine production on human periodontal ligament cells. Int. Immunopharmacol. 10, 744-750. doi: 10.1016/j.intimp.2010.04.004

Roback, J. D., and Guarner, J. (2020). Convalescent plasma to treat COVID-19: possibilities and challenges. JAMA 323, 1561-1562. doi: 10.1001/jama.2020. 4940

Rojas, M., Rodríguez, Y., Monsalve, D. M., Acosta-Ampudia, Y., Camacho, B., Gallo, J. E., et al. (2020). Convalescent plasma in Covid-19: possible mechanisms of action. Autoimmun. Rev. 19:102554. doi: 10.1016/j.autrev.2020.102554

Rosa, S. G. V., and Santos, W. C. (2020). Clinical trials on drug repositioning for COVID-19 treatment. Rev. Panam. Salud Publica 44:e40.

Rothan, H. A., and Byrareddy, S. N. (2020). The epidemiology and pathogenesis of coronavirus disease (COVID-19) outbreak. J. Autoimmun. 109:102433. doi: 10.1016/j.jaut.2020.102433

Sallard, E., Lescure, F.-X., Yazdanpanah, Y., Mentre, F., and Peiffer-Smadja, N. (2020). Type 1 interferons as a potential treatment against COVID-19. Antiviral Res. 178:104791. doi: 10.1016/j.antiviral.2020.104791

Setti, L., Passarini, F., De Gennaro, G., Barbieri, P., Perrone, M. G., Borelli, M., et al. (2020). A. Miani, Airborne transmission route of COVID-19: why 2 meters/6 feet of inter-personal distance could not be enough. Int. J. Environ. Res. Public Health 17:2932. doi: 10.3390/ijerph17082932

Shah, B., Modi, P., and Sagar, S. R. (2020). In silico studies on therapeutic agents for COVID-19: Drug repurposing approach. Life Sci. 252:117652. doi: 10.1016/ j.lfs.2020.117652

Shannon, A., Tuyet Le, N. T., Selisko, B., Eydoux, C., Alvarez, K., Guillemot, J.C., et al. (2020). Remdesivir and SARS-CoV-2: structural requirements at both nsp12 RdRp and nsp14 Exonuclease active-sites. Antiviral Res. 178:104793. doi: 10.1016/j.antiviral.2020.104793

Shen, C., Wang, Z., Zhao, F., Yang, Y., Li, J., Yuan, J., et al. (2020). Treatment of 5 Critically Ill patients with COVID-19 with convalescent plasma. JAMA 323, 1582-1589.

Singh, A. K., Singh, A., Shaikh, A., Singh, R., and Misra, A. (2020). Chloroquine and hydroxychloroquine in the treatment of COVID-19 with or without diabetes: A systematic search and a narrative review with a special reference to India and other developing countries. Diabetes Metab. Syndr. Clin. Res. Rev. 14, 241-246. doi: 10.1016/j.dsx.2020.03.011

Song, Y., Zhang, M., Yin, L., Wang, K., Zhou, Y., Zhou, M., et al. (2020). COVID19 treatment: close to a cure? - a rapid review of pharmacotherapies for the novel coronavirus department of pharmacy services. Int. J. Antimicrob. Agents 56:106080. doi: 10.1016/j.ijantimicag.2020.106080

Soo, Y. O. Y., Cheng, Y., Wong, R., Hui, D. S., Lee, C. K., Tsang, K. K. S., et al. (2004). Retrospective comparison of convalescent plasma with continuing highdose methylprednisolone treatment in SARS patients. Clin. Microbiol. Infect. 10, 676-678. doi: 10.1111/j.1469-0691.2004.00956.x

Spezzani, V., Piunno, A., and Iselin, H.-U. (2020). Benign COVID-19 in an immunocompromised cancer patient - the case of a married couple. Swiss Med. Wkly. 150:w20246.

Stebbing, J., Krishnan, V., de Bono, S., Ottaviani, S., Casalini, G., Richardson, P. J., et al. (2020). Mechanism of baricitinib supports artificial intelligence-predicted testing in COVID-19 patients. EMBO Mol. Med. 12:e12697. doi: 10.21203/rs.3. rs-23195/v1

Taghizadeh-Hesary, F., and Akbari, H. (2020). The powerful immune system against powerful COVID-19: a hypothesis. Med. Hypotheses 140:109762. doi: 10.1016/j.mehy.2020.109762
Tanne, J. H. (2020). Covid-19: FDA approves use of convalescent plasma to treat critically ill patients. $B M J$ 368:m1256. doi: 10.1136/bmj.m1256

Tian, X., Li, C., Huang, A., Xia, S., Lu, S., Shi, Z., et al. (2020). Potent binding of 2019 novel coronavirus spike protein by a SARS coronavirus-specific human monoclonal antibody. Emerg. Microbes Infect. 9, 382-385. doi: 10.1080/ 22221751.2020 .1729069

Touret, F., and de Lamballerie, X. (2020). Of chloroquine and COVID-19. Antiviral Res. 177:104762.

ul Qamar, M. T., Alqahtani, S. M., Alamri, M. A., and Chen, L.-L. (2020). Structural basis of SARS-CoV-2 3CLpro and anti-COVID-19 drug discovery from medicinal plants. J. Pharm. Anal. 10, 313-319. doi: 10.1016/j.jpha.2020. 03.009

van Doremalen, N., Bushmaker, T., Morris, D. H., Holbrook, M. G., Gamble, A., Williamson, B. N., et al. (2020). Aerosol and surface stability of SARS-CoV-2 as compared with SARS-CoV-1. N. Engl. J. Med. 382, 1564-1567.

Vellingiri, B., Jayaramayya, K., Iyer, M., Narayanasamy, A., Govindasamy, V., Giridharan, B., et al. (2020). COVID-19: A promising cure for the global panic. Sci. Total Environ. 725:138277. doi: 10.1016/j.scitotenv.2020.138277

Vincent, M. J., Bergeron, E., Benjannet, S., Erickson, B. R., Rollin, P. E., Ksiazek, T. G., et al. (2005). Chloroquine is a potent inhibitor of SARS coronavirus infection and spread. Virol. J. 2:69.

Walmrath, D., Günther, A., Ghofrani, H. A., Schermuly, R., Schneider, T., Grimminger, F., et al. (1996). Bronchoscopic surfactant administration in patients with severe adult respiratory distress syndrome and sepsis. Am. J. Respir. Crit. Care Med. 154, 57-62. doi: 10.1164/ajrccm.154.1.8680699

Wang, C., Li, W., Drabek, D., Okba, N. M. A., van Haperen, R., Osterhaus, A. D. M. E., et al. (2020). A human monoclonal antibody blocking SARS-CoV-2 infection. Nat. Commun. 11:2251.

Wang, L., Wang, Y., Ye, D., and Liu, Q. (2020). A review of the 2019 Novel Coronavirus (COVID-19) based on current evidence. Int. J. Antimicrob. Agents 55:105948.

Wang, M., Cao, R., Zhang, L., Yang, X., Liu, J., Xu, M., et al. (2020). Remdesivir and chloroquine effectively inhibit the recently emerged novel coronavirus (2019-nCoV) in vitro. Cell Res. 30, 269-271. doi: 10.1038/s41422-0200282-0

Wang, Z., Chen, X., Lu, Y., Chen, F., and Zhang, W. (2020a). Clinical characteristics and therapeutic procedure for four cases with 2019 novel coronavirus pneumonia receiving combined Chinese and Western medicine treatment. Biosci. Trends 14, 64-68. doi: 10.5582/bst.2020.01030

Wang, Z., Yang, B., Li, Q., Wen, L., and Zhang, R. (2020b). Clinical features of 69 cases with coronavirus disease 2019 in Wuhan, China. Clin. Infect. Dis. an Off. Publ. Infect. Dis. Soc. Am. 71, 769-777. doi: 10.1093/cid/ciaa272

WHO (2020). WHO/Europe | Coronavirus disease (COVID-19) outbreak - WHO announces COVID-19 outbreak a pandemic. Available online at: https://www. euro.who.int/en/health-topics/health-emergencies/coronavirus-covid-19\# (accessed October 28, 2020).

Wong, K. Z., and Chu, J. J. H. (2018). The interplay of viral and host factors in chikungunya virus infection: targets for antiviral strategies. Viruses 10:294. doi: 10.3390/v10060294

Wu, C., Liu, Y., Yang, Y., Zhang, P., Zhong, W., Wang, Y., et al. (2020). Analysis of therapeutic targets for SARS-CoV-2 and discovery of potential drugs by computational methods. Acta Pharm. Sin. B 10, 766-788. doi: 10.1016/j.apsb. 2020.02 .008

Xu, X., Han, M., Li, T., Sun, W., Wang, D., Fu, B., et al. (2020). Effective treatment of severe COVID-19 patients with tocilizumab. Proc. Natl. Acad. Sci. U.S.A. 117, 10970-10975.

Yao, X., Ye, F., Zhang, M., Cui, C., Huang, B., Niu, P., et al. (2020). In vitro antiviral activity and projection of optimized dosing design of hydroxychloroquine for the treatment of severe acute respiratory syndrome coronavirus 2 (SARS-CoV2). Clin. Infect. Dis. 71, 732-739. doi: $10.1093 / \mathrm{cid} /$ ciaa237

Ye, X.-T., Luo, Y.-L., Xia, S.-C., Sun, Q.-F., Ding, J.-G., Zhou, Y., et al. (2020). Clinical efficacy of lopinavir/ritonavir in the treatment of Coronavirus disease 2019. Eur. Rev. Med. Pharmacol. Sci. 24, 3390-3396.

Yuan, J., Zou, R., Zeng, L., Kou, S., Lan, J., Li, X., et al. (2020). The correlation between viral clearance and biochemical outcomes of 94 COVID-19 infected discharged patients. Inflamm. Res. Off. J. Eur. Histamine Res. Soc. 69, 599-606. doi: 10.1007/s00011-020-01342-0

Zhai, P., Ding, Y., Wu, X., Long, J., Zhong, Y., and Li, Y. (2020). The epidemiology, diagnosis and treatment of COVID-19. Int. J. Antimicrob. Agents 55:105955. doi: 10.1016/j.ijantimicag.2020.105955 
Zhang, C., Wu, Z., Li, J.-W., Zhao, H., and Wang, G.-Q. (2020). The cytokine release syndrome (CRS) of severe COVID-19 and interleukin-6 receptor (IL6R) antagonist Tocilizumab may be the key to reduce the mortality. Int. J. Antimicrob. Agents 55:105954. doi: 10.1016/j.ijantimicag.2020.105954

Zhang, J., Zhou, L., Yang, Y., Peng, W., Wang, W., and Chen, X. (2020). Therapeutic and triage strategies for 2019 novel coronavirus disease in fever clinics. Lancet Respir. Med. 8, e11-e12.

Zhang, X., Song, K., Tong, F., Fei, M., Guo, H., Lu, Z., et al. (2020). First case of COVID-19 in a patient with multiple myeloma successfully treated with tocilizumab. Blood Adv. 4, 1307-1310. doi: 10.1182/bloodadvances.20200 01907

Zhao, Q., and He, Y. (2020). Challenges of convalescent plasma therapy on COVID-19. J. Clin. Virol. 127:104358. doi: 10.1016/j.jcv.2020.104358

Zhao, S., Lin, Q., Ran, J., Musa, S. S., Yang, G., Wang, W., et al. (2020). Preliminary estimation of the basic reproduction number of novel coronavirus (2019-nCoV) in China, from 2019 to 2020: a data-driven analysis in the early phase of the outbreak. Int. J. Infect. Dis. 92, 214-217. doi: 10.1016/j.ijid.2020.01.050

Conflict of Interest: The authors declare that the research was conducted in the absence of any commercial or financial relationships that could be construed as a potential conflict of interest.

Copyright (c) 2020 Kotta, Aldawsari, Badr-Eldin, Alhakamy, Md, Nair and Deb. This is an open-access article distributed under the terms of the Creative Commons Attribution License (CC BY). The use, distribution or reproduction in other forums is permitted, provided the original author(s) and the copyright owner(s) are credited and that the original publication in this journal is cited, in accordance with accepted academic practice. No use, distribution or reproduction is permitted which does not comply with these terms. 